\title{
Effect of Power Law Fluids Rheology on the Structure of Cuttings and Drilling Fluid Flow in Wellbore Eccentric Annulus
}

\author{
تأثير ريولوجيا السوائل الأسية على هيكل سريان سوائل ونواتح الحفر فى الحي$$
\text { المجري الحلقى غير المثمركز لثقوب الحفر }
$$ \\ by \\ Mohamed L. H. Sakr ${ }^{1 *}$, A. A. Sultan ${ }^{2}$, M. A. Tolba ${ }^{2}$, and M. A. Badawy ${ }^{3}$ \\ ${ }^{1}$ PhD student, Mechanical Engineering Dept, Mansoura Univ., Mansoura, Egypt, \\ Mlsakr@msn.com \\ ${ }^{2}$ Mechanical Engineering Dept, Mansoura Univ., Mansoura, Egypt \\ ${ }^{3}$ Former head of AlAlamin Oil Co., Egypt
}

\begin{abstract}
$\underline{\text { Abstract }}$
Two phase flow of drilling fluids and cuttings in the eccentric annulus between the drill hole and drill pipe is studied. The effect of drilling fluids rheological parameters upon flow structure using the power law rheological model is investigated. Axial velocity distribution of both drilling fluids and cuttings are examined in the presence of drill pipe rotation. Cuttings volume fraction distributions as well as flow contours are considered. Numerical simulation of the two phase turbulent flow is carried out using the Realizable $k-\varepsilon$ model using the computational fluid dynamics software Fluent 6.3.26. The eccentric annulus has inner and outer diameters of $5 \mathrm{~cm}$ and $10 \mathrm{~cm}$ and $50 \%$ eccentricity.
\end{abstract}

The results show that the velocity distributions of both drilling fluids and cuttings, as well as, drilled cuttings volumetric fraction distribution are strongly affected by the rheology of the drilling fluid. It has been verified that power law fluid consistency $k_{p}$ and flow index $(n)$ are significant parameters in determining the local flow structure in the different regions of the annulus. Increasing fluids viscosity reduces the difference between the velocity distributions of drilling fluid and that of cuttings. The effect is more pronounced for the flow with large size cuttings.

Keywords: Two phase flow, Power law fluid, Non-Newtonian fluid, Eccentric annular flow; Computational fluid dynamic (CFD).

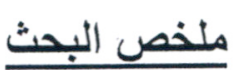

يقدم البحث دراسة عددية لتأثير ريولوجيا السوائل الأسية على هيكل السريان ثنائى الطور لسوائل ونواتج

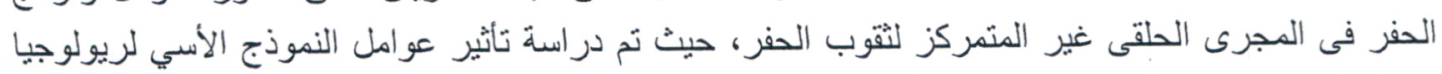

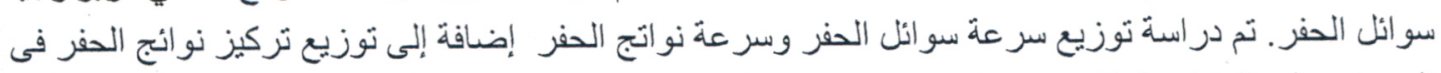

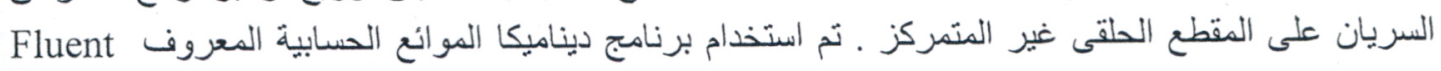

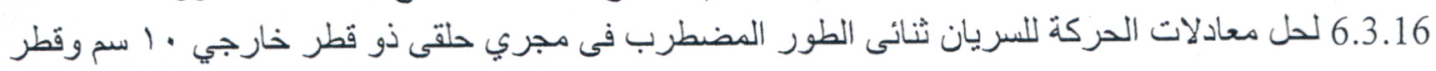

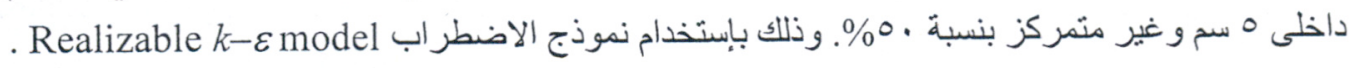

توضح النتائج أن التوزيع المقطعى لسرعة سوائل الحفر وسرعة نو اتج الحفر إضافة إلى التوزيع المقطعى

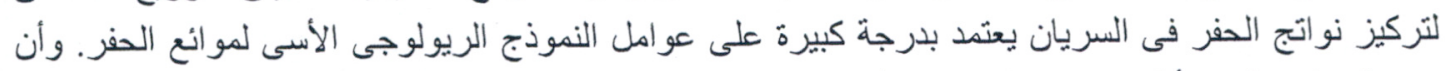

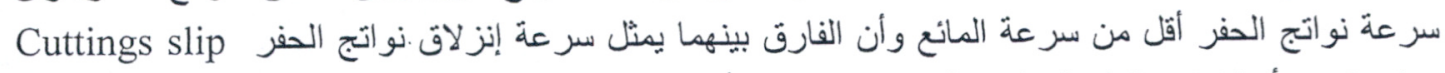

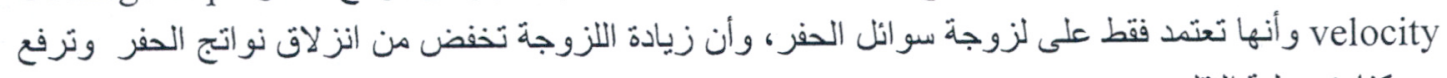

من كفاءة عملية النقل.

Accepted June 13, 2012 


\section{2 Mohamed L. H. Sakr, A. A. Sultan, M. A. Tolba and M. A. Badawy}

\section{Introduction}

Cuttings transport through the annulus passage between drill hole and drill pipe is one of the most important factors that affect drill hole cleaning and drilling operations efficiency. Transport of cuttings by drilling fluids is affected by many parameters, such as well geometry, cuttings characteristics, drilling fluid properties, and drilling operational parameter. Optimization of drilling hydraulics design requires good understanding of the mechanics of cuttings transport. It has been recognized that drilling fluids rheology greatly affects the flow structure and the transport process of drilled cuttings in drill hole annulus.

Drilling fluids exhibit non-Newtonian behavior. Rheological classifications of drilling fluids are carried out by Lauzon and Reid (1979). They evaluated experimentally the accuracy of defining drilling muds by various known rheological models. They found that the power-law model is more than accurate to represent the rheology of drilling fluid flow in drill hole annulus.

Piggott (1941) was the first to study drilling mud flow in pipes, wellbores, and mud pits, and presented the results of drilling mud hydraulics in pipe and annulus. He concluded that raising mud velocity and density was most beneficial for cuttings removal. High viscosity either in laminar or turbulent flow was undesirable. Clay concentration has significant effect on pressure loss in laminar flow, but for turbulent flow, little more pressure loss was observed due to the presence of clay. Piggott stated that $5 \%$ cuttings concentration in the drilling fluid is safe for cuttings transport. Williams and Bruce (1951) investigated the minimum velocity required to remove cuttings successfully and the effects of drilling fluid properties on their carrying capacities. They found that low-gel, low viscosity muds are better than high-gel, high viscosity muds in cuttings removal, and pipe rotation has a strong positive impact on cuttings transport. Hopkin experimental results showed a minimum of $0.61 \mathrm{~m} / \mathrm{s}$ velocity required with low. viscosity drilling fluid. He reported that high viscosity mud in laminar region is more favorable than lower viscosity fluid in turbulent flow for hole cleaning, which was not in agreement with Williams and Bruce's conclusions.

Tomren et al. (1986) carried out experimental studies using actual drilling fluids and the cuttings concentration in the annulus as an index for the evaluation of the carrying capacity of the fluid. They concluded that the major factors affecting the carrying capacity of drilling fluids are fluid velocity and mud rheology. Hemphill and Larsen (1993) performed experimental study using oil-based and water-based drilling fluids. They concluded that fluid velocity and the power law index of the fluid are the significant factors affecting hole cleaning, and recommended using power law model to represent the rheology of drilling fluids. Attention was focused on prediction of the rheology effects and flow rates on drilling operations by knowing the slip velocity of the cuttings [Azar and Sanchez (1997)]. Sample and Bourgoyne 
(1977) and (1978) developed correlations for slip velocity, related to cuttings transport efficiency in vertical wells, between fluid rheology and physical characteristics of drilled cuttings.

Recognizing the role of fluid velocity in cleaning an annulus where the drillpipe is off-center or eccentric, others have studied the distribution of annular point velocities [Haciislamoglu (1989), Azouz et al. (1993), Vinod (1994)]. It had been recognized that the flow index, (from the Herschel-Bulkley and Power-law rheological models) controls the flow distribution in an annulus when the inner pipe is eccentric. Vinod (1994) studied numerically the effect of fluids rheology on the efficiency of the transport of drill bit cuttings. Results show that power law index is a significant parameter in determining the local flow regime in the different regions of the annulus. Hence accurate control of power law index is critical in optimizing bore hole flow. In laminar flow, the shear thinning nature of a fluid does not aid flow through the narrow regions. Turbulence in the wider regions of the annuli aids flow through the narrow regions. The wall shear stresses are dependent only on the pressure drop, gap width and the local flow regimes. Eccentricity is found to slow down flow through the narrow regions of the annuli and certain combinations of rheology and eccentricity can cause stationary 'plug like' zones inside the annuli.

Sanchez et al. (1999) investigated the effect of drill pipe rotation on hole cleaning while drilling directional wells. The results showed that the drill pipe rotation had a considerable effect on hole cleaning. Wang et al. (2009) applied CFD to simulate solidliquid two-phase flows in wellbore annulus. The annual flow field with the presence of drillpipe rotation is described through analyzing various rotation conditions. Comparisons with previously published results proved the importance of drillpipe rotation in the wellbore clearing. They stated that the rotation of the drillpipe, and hydraulic and rheological parameters, are the key factors for wellbore cleaning.

Okrajni and Azar (1986) investigated the effects of mud rheology on hole cleaning in directional well. The results revealed that drilling fluid rheological properties generally did not affect the cuttings transport in turbulent flow, although the drilling fluid with higher yield value gives better cuttings transport in laminar flow. Brown et al. (1989) observed that hole cleaning was more efficient with water in turbulent flow than with hydroxyethyl cellulose (HEC) based drilling fluid. Bentonite is added to drilling fluids for viscosity control, to aid the cuttings transport and for filtration control to prevent filtration of drilling fluids into formations.

Pérez et al (2004) studied experimentally the flow of guar gum solutions and sand in the annular space of a concentric-pipe system. Amundarain et al. (2009) investigated the effect of rheology of Xanthan gum and guar gum mixtures on solids transport in vertical annular flows of sand/water suspensions. The results show 


\section{4 Mohamed L. H. Sakr, A. A. Sultan, M. A. Tolba and M. A. Badawy}

that solids suspension capacity of the solutions is enhanced by the presence of polymer. The addition of guar gum decreases the minimum annular velocity needed to achieve a homogeneous axial solids distribution in the annular region. The results also show that relatively high viscosities, and high polymer relaxation times are desired rheological characteristics for a drilling fluid to obtain a uniform solids distribution in the annulus, as well as high solids carrying capacity.

Velocity distributions of Newtonian and non-Newtonian fluids in eccentric annuli are considered in several publications. It should be noted that all the studies previously discussed considered velocity profiles with only liquid flowing inside the eccentric annulus [Sakr (2008)]. Effects of solid particles in the flow stream were not included. Newitt et al. (1961) presented relationships which showed that the presence of solids up to 10 percent by volume had little or no effect on the velocity distribution. For particle concentrations over 15 percent, the velocity profile was flattened even in laminar flow. Mitsuishi and Aoyagi (1973) carried out detailed experimental study of velocity profiles in eccentric annuli. They measured point velocities of nonNewtonian CMC solutions using hydrogen bubbles and showed that velocities are lower in the narrow section of an eccentric annulus, the reduction in velocity depending on eccentricity and pipe diameter ratios. They also showed that the pressure drop for flow in an eccentric annulus decreased as the eccentricity increased at any given flow rate. Fluids with stronger non-Newtonian properties showed a slower rate of pressuredrop decrease as eccentricity increased.

The above discussion revealed that none have investigated the flow structure in wellbore annulus, and there is a need for studies to investigate the effect of drilling fluid rheology on the drilling fluids and cuttings flow structure. The objectives of this study are to investigate numerically the influence of drilling fluid rheology and the power law model parameters upon the structure of drilling flow and cuttings in wellbore eccentric annulus, and to understand their role on hole cleaning.

\section{Problem Description}

The flow structure of the two phase flow of drilling fluids and cuttings in the eccentric annulus drill hole is numerically investigated in the presence of drill pipe rotation $\mathrm{N}=300 \mathrm{rpm}$. The investigated eccentric annular duct that has an inner diameter $D_{i}=5 \mathrm{~cm}$ and outer diameter $D_{o}=10 \mathrm{~cm}$ and length $\mathrm{L}=500 \mathrm{~cm}$. The eccentricity of the annular passage is $50 \%$. The geometry of the eccentric annulus is shown in Figure (1). Numerical simulation is carried out using Fluent 6.3.26 CFD commercial software package [FLUENT (2006)]. The flow is assumed to be turbulent, and computations are carried out using the realizable $k-\varepsilon$ model.

Drilling fluids are complex mixtures of various types of base fluids and additives, and they are characterized as nonNewtonian fluids. Drilling fluids rheology is described by many rheological models. The 
most commonly and widely used models in oil industry are Bingham plastic model, the Power law model and the Herschel-Bulkley model. It has been experimentally verified that power law model is sufficiently accurate to represent high shear rate encountered in drilling operations (Lauzon and Reid (1979)). Power law model is adopted to represent the rheology of drilling fluids. The constitutive equation for the power law model and the apparent viscosity relationship are given as.

$$
\begin{aligned}
& \tau=K_{p} \cdot \gamma^{n} \\
& \mu_{a}=K_{p} \cdot \gamma^{n-1}
\end{aligned}
$$

Where, $\tau$ is the shear stress, $\gamma$ is the strain rate, $K_{p}$ is called the fluid consistency and $n$ the flow index.

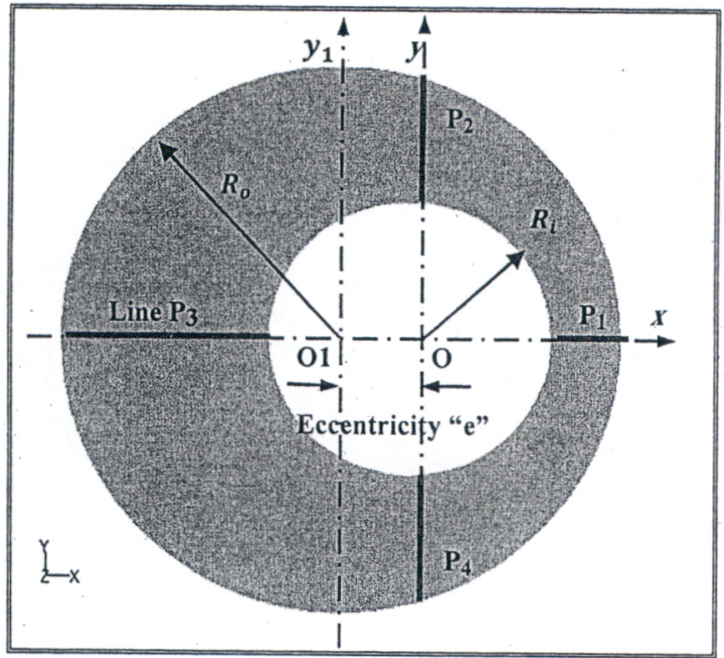

Figure (1)

The geometry of the eccentric annulus

\section{Mathematical Modeling}

The two phase flow of drilling fluids and cuttings in the eccentric passage of the drill hole is studied using granular-Eulerian model. The Eulerian two-phase model assumes that the flow consists of solid cuttings $(s)$ and drilling fluid $(f)$ phases, are separate, but form interpenetrating continua, such that the volumetric concentrations of the fluid and solid phases $\alpha_{f}$ and $\alpha_{s}$ are related by

$$
\alpha_{f}+\alpha_{s}=1
$$

The numerical model allows the determination of the pressure and velocity of the solid as well as liquid phases by using the commercial CFD software FLUENT. The laws for the conservation of mass and momentum are satisfied by each phase individually. Coupling is achieved by pressure and inter-phases exchange coefficients. The conservation equations governing the two-phase flow of drilling fluid and cuttings are presented in the general form as following:

\subsection{Conservation of mass}

$$
\begin{gathered}
\frac{\partial}{\partial t}\left(\alpha_{q} \rho_{q}\right)+\nabla \cdot\left(\alpha_{q} \rho_{q} \vec{U}_{q}\right)= \\
\sum_{p=1}^{n} \dot{m}_{p q}
\end{gathered}
$$

where $\vec{U}_{q}$ is the velocity of phase $q$ and $\dot{m}_{p q}$ characterizes the mass transfer from the $p$ to $q$ phase. By default, the source term on the right-hand side of Equation (4) is zero,

\subsection{Conservation of momentum:}

For liquid phase "f"

$$
\begin{gathered}
\frac{\partial}{\partial t}\left(\alpha_{f} \rho_{f} \vec{U}_{f}\right)+\nabla \cdot\left(\alpha_{f l} \rho_{f} \vec{U}_{f} \vec{U}_{f}\right)= \\
-\alpha_{f} \nabla p+\nabla \cdot T_{f}+ \\
\alpha_{f} \rho_{f} \vec{g}+K_{s f}\left(\vec{U}_{s}-\vec{U}_{f}\right)+ \\
\alpha_{f} \rho_{f}\left(\vec{F}_{f}+\vec{F}_{l i f t, f}+\right. \\
\left.\vec{F}_{v m, f}\right)
\end{gathered}
$$


For the solid phase " $s$ "

$$
\begin{gathered}
\frac{\partial}{\partial t}\left(\alpha_{s} \rho_{s} \vec{U}_{s}\right)+\nabla \cdot\left(\alpha_{s} \rho_{s} \vec{U}_{s} \vec{U}_{s}\right)= \\
-\alpha_{s} \nabla p-\nabla p_{s}+\nabla \cdot T_{s}+ \\
\alpha_{s} \rho_{s} \vec{g}+K_{f s}\left(\vec{U}_{f}-\vec{U}_{s}\right)+ \\
\alpha_{s} \rho_{s}\left(\vec{F}_{s}+\vec{F}_{l i f t, s}+\vec{F}_{v m, s}\right)
\end{gathered}
$$

\subsection{The stress-strain tensor $T_{q}$ of the} liquid phase "f $\mathrm{f}$ " and solid phase " $\mathrm{s}$ " is given as

$$
\begin{array}{r}
T_{q}=\alpha_{q} \mu_{q}\left(\nabla \vec{U}_{q}+\nabla \vec{U}_{q}^{T}\right)+ \\
\alpha_{q}\left(\lambda_{q}-\frac{2}{3} \mu_{q}\right) \nabla \cdot \vec{U}_{q} \overline{\bar{I}}
\end{array}
$$

where, $\mu_{q}$ and $\lambda_{q}$ are the shear and bulk viscosity of the liquid phase " $f$ ", or solid phase " $s$ ", $\vec{F}_{f}$ and $\vec{F}_{s}$ are external body force for liquid and solid phases, $\vec{F}_{\text {lift,f }}$ and $\vec{F}_{\text {lift }, s}$ are the lift force for liquid and solid phases, $\vec{F}_{v m, f}$ and $\vec{F}_{v m, s}$ are the virtual mass force for liquid and solid phases, $p$ is the pressure shared by all phases and $p_{s}$ is the solids pressure. $K_{s f}$ and $K_{f s}$ are the momentum exchange coefficient between liquid phase "f" and solid phase " $s$ ", and vise versa.

The lift force $\vec{F}_{\text {lift }}$ is neglected in most cases when compared to the drag force. The virtual mass force $F_{v m}$ on the particles is neglected due to the fact that it is significant only when the secondary phase density is much smaller than the primary phase density.

For granular flow, the fluid-solid exchange coefficient $K_{s f}$ is function of the solid particles relaxation time $\tau_{s}$ and written in the following general form as [Fluent (2006)].

$$
\begin{gathered}
K_{s l}=\frac{\alpha_{s} \rho_{s} \phi}{\tau_{s}} \\
\tau_{s}=\frac{\rho_{s} d_{s}^{2}}{18 \mu_{f}}
\end{gathered}
$$

where $d_{s}$ is the diameter of particles of phase $s$,

Different models for the exchangecoefficient " $\phi$ " have been developed. All include a drag function " $C_{D}$ " that is based on the relative Reynolds number $\left(R e_{S}\right)$. The drag coefficient $C_{D}$ differs among the exchange-coefficient models. The one adopted in this study is that of Gidaspow model [Gidaspow et al. (1992)].

When, $\alpha_{f}>0.8$, fluid-solid exchange coefficient $K_{s f}$ is

$$
\begin{aligned}
& K_{S f}=\frac{3}{4} C_{D} \frac{\alpha_{s} \alpha_{f} \rho_{f}\left|\vec{U}_{s}-\vec{U}_{f}\right|}{d_{s}} \alpha_{f}^{-2.65} \\
& C_{D}=\frac{24}{\alpha_{f} R e_{s}}\left[1+0.15\left(\alpha_{f} R e_{s}\right)^{0.687}\right]
\end{aligned}
$$

The relative Reynolds number $R e_{s}$ is:

$$
R e_{s}=\frac{\rho_{f} d_{s}\left|\vec{U}_{s}-\vec{U}_{f}\right|}{\mu_{f}}
$$

When $\alpha_{f} \leq 0.8$,

$$
\begin{aligned}
K_{s f}= & 150 \frac{\alpha_{s}\left(1-\alpha_{f}\right) \mu_{f}}{\alpha_{f} d_{s}^{2}}+ \\
& 1.75 \frac{\rho_{f} \alpha_{s}\left|\vec{U}_{s}-\vec{U}_{f}\right|}{d_{s}} \\
K_{f s}= & K_{s f}
\end{aligned}
$$

For granular flows, the solids pressure is composed of a kinetic term and a second term due to particle collisions.

$$
\begin{aligned}
p_{s}=\alpha_{s} \rho_{s} \Theta_{s} & +2 \rho_{s}(1 \\
& \left.+e_{s s}\right) \cdot \alpha_{s}^{2} g_{0 ; s s} \Theta_{s}
\end{aligned}
$$


where $e_{s s}$ is the coefficient of restitution for particle collisions $\left(e_{s s}=0.9\right), g_{0, s s}$ is the radial distribution function, and $\Theta_{S}$ is the granular temperature, which is proportional to the kinetic energy of the fluctuating particle motion.

The radial distribution function, $g_{0}$, is a correction factor that modifies the probability of collisions between grains when the solid granular phase becomes dense. This function is given by [Ogawa et al (1980)]:

$$
g_{0}=\left[1-\left(\frac{\alpha_{s}}{\alpha_{s, \max }}\right)^{\frac{1}{3}}\right]^{-1}
$$

The solids stress tensor contains shear and bulk viscosities arising from particle momentum exchange due to translation and collision. A frictional component of viscosity can also be included to account for the viscous-plastic transition that occurs when particles of a solid phase reach the maximum solid volume fraction. The collisional, kinetic, and the optional frictional parts are added to give the solids shear viscosity $\mu_{s}$ :

$$
\mu_{s}=\mu_{s, c o l}+\mu_{s, k i n}+\mu_{s, f r}
$$

The collision shear viscosity is modeled as [Syamlal et al. (1993)]

$$
\begin{aligned}
\mu_{s, \mathrm{col}}=\frac{4}{5} \alpha_{s} \rho_{s} d_{s} g_{0, s s}(1 \\
\left.+e_{S S}\right)\left(\frac{\Theta_{S}}{\pi}\right)^{0.5}
\end{aligned}
$$

Syamlal et al. (1993) expression for the kinetic viscosity is

$$
\begin{aligned}
& \mu_{s, k i n}=\frac{\alpha_{s} d_{s} \rho_{s} \sqrt{\Theta_{s} \pi}}{6\left(3-e_{s s}\right)} \cdot C_{1} \\
& C_{1}=\left[1+\frac{2}{5}\left(1+e_{s s}\right)\left(3 e_{s s}-1\right) \alpha_{s} g_{0, s s}\right]
\end{aligned}
$$

Schaeffer's (1987) expression is considered for the friction viscosity

$$
\mu_{s, f r}=\frac{p_{s} \cdot \sin \theta}{2 \sqrt{I_{2 D}}}
$$

where $p_{s}$ is the solids pressure, $\theta$ is the angle of internal friction, and $I_{2 D}$ is the second invariant of the deviatoric stress tensor. It is also possible to specify a constant or user-defined frictional viscosity.

The solids bulk viscosity accounts for the resistance of the granular particles to compression and expansion. It has the following form of Lun et al. [Lun et al (1984)]:

$$
\begin{gathered}
\lambda_{s}=\frac{4}{3} \alpha_{s} \rho_{s} d_{s} g_{0, s s}(1+ \\
\left.e_{s s}\right)\left(\frac{\Theta_{s}}{\pi}\right)^{\frac{1}{2}}
\end{gathered}
$$

Predictions for turbulent quantities for the fluid phase are obtained using the realizable $k-\varepsilon$ model [Fluent (2006)]. To predict the turbulence of solid phase, Tchen's theory of the dispersion of discrete particles in homogeneous and steady turbulent flow is used. In this study, modeling turbulence in multiphase flows is considered using dispersed turbulence realizable $k-\varepsilon$ model. The eddy viscosity model is used to calculate averaged fluctuating quantities. The Reynolds stress tensor for continuous phase " $f$ " takes the following form: 


$$
\begin{gathered}
T_{f}^{\prime}=-\frac{2}{3}\left(\rho_{f} k_{f}+\rho_{f} \mu_{t, f} \nabla \cdot \vec{U}_{f}\right) \overline{\bar{I}}+ \\
\rho_{f} \mu_{t, f}\left(\nabla \vec{U}_{f}+\nabla \vec{U}_{f}^{T}\right)
\end{gathered}
$$

The turbulent viscosity $\mu_{t, f}$ is written in terms of the turbulent kinetic energy of liquid phase, and the characteristic time and length scales of turbulent eddies $\tau_{t, f}$ and $L_{t, f}$ are defined as

$$
\begin{aligned}
\mu_{t, f} & =\rho_{f} C_{\mu} \frac{k_{f}^{2}}{\varepsilon_{f}} \\
\tau_{t, f} & =\frac{3}{2} C_{\mu} \frac{k_{f}}{\varepsilon_{f}} \\
L_{t, f} & =\sqrt{\frac{3}{2}} C_{\mu} \frac{k_{f}^{3 / 2}}{\varepsilon_{f}}
\end{aligned}
$$

where $\varepsilon_{f}$ is the dissipation rate of the liquid phase and $C_{\mu}=0: 09$

Turbulence predictions are obtained from the modified $k-\varepsilon$ model equations as:

and

$$
\begin{gathered}
\frac{\partial}{\partial t}\left(\alpha_{f} \rho_{f} k_{f}\right)+\nabla \cdot\left(\alpha_{f} \rho_{f} \vec{U}_{f} k_{f}\right)= \\
\nabla \cdot\left(\alpha_{f} \frac{\mu_{t, f}}{\sigma_{\varepsilon}} \nabla k_{f}\right)+ \\
\alpha_{f} G_{k, f}-\alpha_{f} \rho_{f} \varepsilon_{f}+ \\
\alpha_{f} \rho_{f} \Pi_{k, f}
\end{gathered}
$$

$$
\begin{gathered}
\frac{\partial}{\partial t}\left(\alpha_{f} \rho_{f} \varepsilon_{f}\right)+\nabla \cdot\left(\alpha_{f} \rho_{f} \vec{U}_{f} \varepsilon_{f}\right)= \\
\nabla \cdot\left(\alpha_{f} \frac{\mu_{t, f}}{\sigma_{\varepsilon}} \nabla \varepsilon_{f}\right)+ \\
\alpha_{f} \frac{\varepsilon_{f}}{k_{f}}\left(C_{1 \varepsilon} G_{k, f}-\right. \\
\left.C_{2 \varepsilon} \rho_{f} \varepsilon_{f}\right)+\alpha_{f} \rho_{f} \Pi_{\varepsilon, f}
\end{gathered}
$$

$\Pi_{k, f}$ and $\Pi_{\varepsilon, f}$ represent the influence of the dispersed phases on the continuous liquid phase $f$, and $G_{k, f}$ is the production of turbulent kinetic energy. All other terms have the same meaning as in the single- phase $k-\varepsilon$ model. The term $\Pi_{k, f}$ can be derived from the instantaneous equation of the continuous phase and takes the following simplified form for single secondary phase,

$$
\begin{aligned}
& \Pi_{k, f}=\frac{K_{s f}}{\alpha_{f} \rho_{f}}\left[k_{s f}-2 k_{f}+\vec{U}_{s f} \cdot \vec{U}_{c}\right. \\
& \Pi_{\varepsilon, f}=C_{3 \varepsilon} \frac{\varepsilon_{f}}{k_{f}} \Pi_{k, f}
\end{aligned}
$$

where, $k_{s f}$ is the covariance of the velocities of the continuous phase $f$ and the dispersed phase $s, \vec{U}_{s f}$ is the relative velocity, model constants $C_{1 \varepsilon}=1.44, C_{2 \varepsilon}=1.9$ and $C_{3 \varepsilon}=$ 1.3 , and $\vec{U}_{d r}$ is the drift velocity and is given by

$$
\begin{aligned}
\vec{U}_{d r}=-\left(\frac{D_{s}}{\sigma_{s f} \alpha_{s}} \nabla \alpha_{s}\right. \\
\left.-\frac{D_{f}}{\sigma_{s f} \alpha_{f}} \nabla \alpha_{f}\right)
\end{aligned}
$$

where $D_{s}$ and $D_{f}$ are solid and liquid diffusivities, and $\sigma_{s f}$ is a dispersion Prandtl number. When using Tchen theory in multiphase flows, it is assumed that $D_{s}=D_{f}=D_{t, s f}$ and $\sigma_{s f}=0.75$.

Time and length scales that characterize the motion are used to the evaluate dispersion coefficients, correlation functions, and turbulent kinetic energy of each dispersed phase. The characteristic particle relaxation time connected with inertial effects acting on a dispersed phase " $s$ " is defined as:

$$
\tau_{F, s f}=\frac{\alpha_{s} \rho_{f}}{K_{s f}}\left(\frac{\rho_{s}}{\rho_{f}}+C_{V}\right)
$$


The Lagrangian integral time scale calculated along particle trajectories, mainly affected by the crossing-trajectory effect [Csanady (1963)], is defined as

$$
\tau_{t, s f}=\frac{\tau_{t, f}}{\sqrt{\left(1+C_{\beta} \xi^{2}\right)}}
$$

where,

$$
\begin{aligned}
& \xi=\frac{\left|\vec{U}_{s f}\right| \tau_{t, f}}{L_{t, l}} \quad \text { and } \\
& C_{\beta}=1.8-1.35 \cos ^{2} \theta_{p}
\end{aligned}
$$

Where, $\theta_{p}$ is the angle between the particle velocity and the relative velocity (in this work, $\theta_{p}=30^{\circ}$ ). The ratio between these two characteristic times is written as

$$
\eta_{s f}=\frac{\tau_{t, s f}}{\tau_{F, s f}}
$$

The turbulence quantities for dispersed phase $s$ are given by Simonin and Viollet (1990) as

$$
\begin{gathered}
k_{s}=k_{f}\left(\frac{b^{2}+\eta_{s f}}{1+\eta_{s f}}\right) \\
k_{s f}=2 k_{f}\left(\frac{b+\eta_{s f}}{1+\eta_{s f}}\right) \\
D_{t, s f}=\frac{1}{3} k_{s f} \cdot \tau_{t, s f} \\
D_{s}=D_{t, s f}+\left(\frac{2}{3} k_{s}\right. \\
\left.-\frac{b}{3} k_{s f}\right) \tau_{F, s f}
\end{gathered}
$$

and

$$
\begin{gathered}
b=\left(1+C_{V}\right)\left(\frac{\rho_{s}}{\rho_{f}}+C_{V}\right)^{-1}, \\
C_{V}=0.5
\end{gathered}
$$

In the near wall region, the gradient of quantities is high, and requires fine grids or special computing treatment. In the present study, the standard wall function proposed by Launder and Spalding (1974) was used. The wall function helps in more precise calculation of near-wall shear stresses for both liquid and solid phases in the Eulerian two-phase model.

No-slip boundary conditions were imposed on all the solid surfaces for the continuous phase. The same conditions were also applied to the discrete phase and imposed on the corresponding momentum equations. The inlet liquid velocity and the outlet pressure were specified. No-slip boundary conditions were assumed at the walls for the liquid phase. Interactions between the particles and the walls were modeled with the same formulation used for solids pressure and granular viscosity for the particle-particle interactions.

\section{Numerical Solution}

The annulus between the drill pipe and the borehole is considered as an eccentric annulus [see Figure (1)]. The governing equations discussed above for the turbulent flow must be solved numerically to predict the flow field and flow parameters. Computational grid was generated using Gambit 2.3.16. Meshing the eccentric annulus passage volume is created with 30 divisions in the radial directions, 120 divisions in the angular direction, and 100 divisions in the axial directions producing 360000 hexahedral cells as shown in Figure (2). For long ducts, hexagonal shape and Cooper-type element have been employed to get better convergence and accuracy. The 
Cooper-type element is a volume-meshing type in Gambit, which uses an algorithm to sweep the mesh node patterns of specified 'source' faces through the volume.

The governing partial differential equations were discretized using finite volume technique. The discretized equations with the initial and boundary conditions were solved using. Fluent 6.3.26. The Eulerian-Eulerian approach for granular flow was used, which allows the determination of the pressure and viscosity of the solids phase. Second-order upwind discretization scheme was used for the momentum equation, and QUICK discretization was used for volume fraction, turbulent kinetic energy and turbulent dissipation energy. These schemes ensured, in general, satisfactory accuracy, stability and convergence. The convergence criterion is based on the residual value of the calculated variables, that is, mass, velocity components, turbulent kinetic energies, turbulent dissipation energies and volume fraction. Convergence criterion of $1 \times 10^{-5}$ was chosen for $r, \theta$ and $z$ velocity components, turbulent energy $\mathrm{k}$, and turbulent dissipation frequency $\omega$ of the two phases as well as the continuity equation. Convergence criteria were achieved after 1350 iterations.

In pressure-velocity coupling the phasecoupled Simple algorithm was used. Other solution strategies are the reduction of under-relaxation factors of momentum, volume fraction, turbulent kinetic energy and turbulent dissipation energy to bring the nonlinear equation close to the linear equation, and subsequently using a better initial guess. Parametric analyses were undertaken to assess the sensitivity of the simulation results to various input parameters, and to determine appropriate default parameters and methodologies for predicting the flow structure and pressure drop.

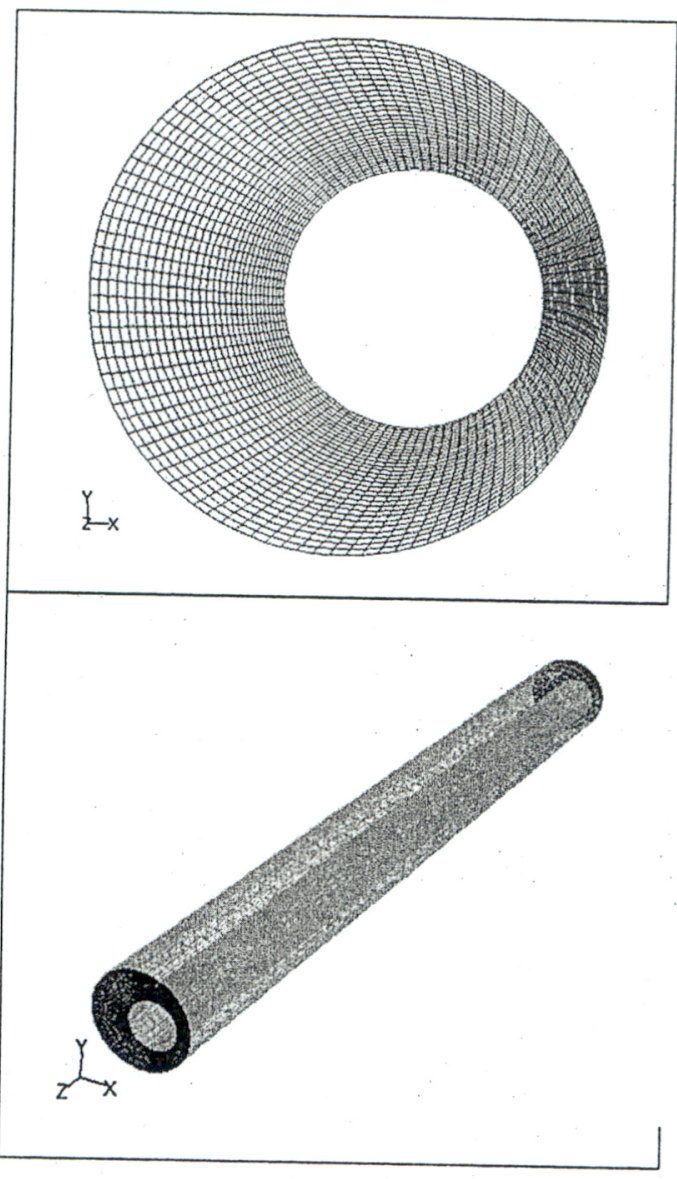

Figure (2)

Mesh structure of the eccentric annulus

\section{Results and Discussions}

The influence of drilling fluid rheology on the flow structure of drilling fluids and cuttings in the eccentric annulus between the hole and drill pipe is studied. Drilling fluid rheology is an important parameter that 
affects the structure of the two phase flow. In this study, fluid rheology is represented by the power law model. This model is characterized by two parameters; the fluid consistency " $k_{p}$ " and the flow index " $n$ ". The effect of drilling fluid density on flow structure is considered. Flow structure results presented are that of the outlet section. The eccentric annular passage considered has an inner diameter $D_{i}=$ $5 \mathrm{~cm}$, outer diameter $D_{o}=10 \mathrm{~cm}$, and length $L=500 \mathrm{~cm}$. The annulus eccentricity is $50 \%$. The average flow velocity is $U_{a v}=2.0 \mathrm{~m} / \mathrm{s}$, cuttings to drilling fluid mass ratio is $m_{r}=0.5$, and cuttings size is $d p=5 \mathrm{~mm}$. Drill pipe rotation is kept constant at $300 \mathrm{rpm}$. Flow Reynolds number was varied from 140 to 110,000 , where $\mathrm{Re}$ is defined as $R e=$ $\left(\rho_{f} . U_{a v} . D_{h}\right) / \mu_{f}$

\subsection{Axial Velocity Profiles and Contours}

\subsubsection{Effect of Fluid Consistency $k_{p}$}

Figure (3) presents the effect of fluid consistency $k_{p}$ of the power law drilling fluid on the axial velocity contours for constant flow index $n=0.5$. For the case of fluids with smaller flow index $n=0.5$, and small values of $k_{p} \quad\left(k_{p}=0.01\right)$, the viscosity is $\mu=0.0009$ Pa.s and Reynolds number is $R e=109,600$. The flow is highly turbulent, the high velocity contours in the wide section are of irregular shape, and the velocity difference between the narrow and wide gaps of the eccentric annulus is small. Increasing fluid consistency constant $k_{p}$ to $0.1,1.0$ and 10, increases fluid viscosity and reduces flow Reynolds number to 13800 ,
1397, and 142 respectively. For fluids with smaller flow index $n=0.5$, and $k_{p}=0.1$, where the flow is turbulent, velocity contours are irregular in shape. Whereas for $k_{p}>0.1$, the flow is laminar and the high velocity region in the wide gap becomes more regular in shape and well defined with increased values of $k_{p}$. The low flow velocity in the narrow gap decreases with increased values of $k_{p}$.

Velocity profiles and cuttings volume fraction distributions are considered at the narrow gap P1, the wide gap section P3 shown in Figure (1). Velocity and cuttings concentration are plotted as function of the normalized radial distance $r_{n}$ defined as $\left[r_{n}=\left(r-r_{\min }\right) /\left(r_{\max }-r_{\min }\right)\right]$. Typical plot of the axial velocity profiles of the drilling fluid at gap sections P1 and P3 of the outlet cross section of the eccentric annular passage is shown in Figure (4). It presents the effect of fluid consistency $k_{p}$ of drilling fluid on the axial velocity distribution for constant flow index $n=0.5$. In the wide section of the annulus, flow velocity is higher than that in the narrow. section. For small values of $k_{p}$, as that of $k_{p}=0.01$ and $n=0.5$, the flow is highly turbulent $(R e=109600)$ and the velocity distribution is almost flat with two peaks close to the inner and outer walls of the annulus.

For fluids with constant flow index $n=0.5$, increasing fluid consistency $k_{p}$ to $0.05,0.1,0.5,1.0,5$ and 10 , increases drilling fluid viscosity, hence reduces flow Re to $24200,13800,2790,1379,285$ and 
142 respectively. As a result, two velocity distribution patterns are recognized, turbulent one for small values of $k_{p}$ up to $k_{p}=0.5$ that corresponds to $R e=2790$, and the other is laminar flow for higher values of $k_{p}$. Turbulent velocity profiles are similar and exhibit two peaks near the walls, whereas, laminar velocity profiles shows distinguishable peak in the middle of all sections. For laminar flow pattern, increasing $k_{p}$, increases the velocity in the wide gap of the annulus P3 and decreases the velocity in the narrow one $\mathrm{P} 1$.

The axial velocity profiles of cuttings (Cuttings) are compared with those of drilling fluid $(D F)$ in figure (5) for different values of fluid consistency $k_{p}$ and fluid index $n=0.5$. Velocity distributions show that, as the distances increase along the radial direction, the velocity increases from zero at the drillpipe wall to maximum value near the center of the stream, then decreases to zero again at the wellbore wall. Since higher fluid velocity yields higher cutting lifting force, cuttings in the center of the stream are transported faster than those close to the wall. It is likely that the fluid velocity near the outer boundaries is not sufficient so that the cuttings would fall back towards the bottom of the hole along the wall.

Results show that cuttings axial velocity is always lower than that of the fluid velocity. The difference between fluid flow velocity " $U$ " and cuttings velocity " $U_{c}$ " is the slip velocity " $V_{S}$ ". Slip velocity is higher near the wall compared to that in the core of the section. For small values of $k_{p}$, slip velocity is high. Increasing $k_{p}$ decreases the difference between flow and cuttings velocities such that the difference is almost zero for $k_{p}>0.5$.

\subsubsection{Effect of Flow Index " $n$ "}

The effect of flow index " $n$ " of drilling fluid on the axial velocity contours is shown in Figure (6) for fluid consistency $k_{p}=1.0$. For fluids with $k_{p}=1.0$ and small values of $n=0.1$ where the viscosity is $\mu=0.0098$ Pa.s, and $R e=10160$, the flow is turbulent. The region of high velocity contours in the wide gap section P3 is of irregular shape. The velocity in the narrow gap section P1 is lower. For fluids with $k_{p}=1.0$, increasing flow index " $n$ " to $0.3,0.5$, and 0.7 reduces $\operatorname{Re}$ to 3925,1407 , and 494 . The first one is turbulent showing irregular shape high velocity region in the wide gap. The other two are laminar characterized by regular confined and well defined region of high velocity. The increase in flow index " $n$ " causes the flow velocity to increase in the wide gap and becomes smaller and smaller in the narrow gap. This clearly demonstrates that the high velocity region has irregular. shape for turbulent flow, and more distinguishable and regular shape for laminar flow. Reducing flow Re number increases the difference between the velocity in the wide section and that in the narrow one.

The effect of flow index $n$ of drilling fluid with $k_{p}=0.3$ on the axial velocity distribution is investigated. Plot of axial velocity profiles of drilling fluid flow at 
narrow and wide gap sections $\mathrm{P} 1$ and $\mathrm{P} 3$ of the outlet cross section is presented in Figure (7). For small values of $n,(n=$ $0.1-0.4$ ), where the viscosity is $\mu=0.0043$ - 0.013 Pa.s and $R e=23130$ - 7600, the velocity distributions at $\mathrm{P} 1$ and $\mathrm{P} 3$ are almost flat with two peaks near the inside and outside walls of the annulus. For large values of $n,(n=0.5-0.8)$, where the viscosity is $\mu=0.021-0.10$ Pa.s and $R e=4690-967$, the velocity distributions at P1 and P3 have laminar shape with peak in the middle of the section. The velocity in the wide section P3 is higher than that in the narrow section $\mathrm{P} 1$ and the difference increases with the increase of flow index " $n$ ".

Axial velocity profiles of cuttings at sections P1-P4, are compared with that of drilling fluid in figure (8) for different values of fluid index " $n$ " at $k_{p}=0.3$. Results show that cuttings velocity is lower than that of the fluid velocity. The difference between flow velocity " $U$ " and cuttings velocity " $U_{c}$ " represents the slip velocity of cuttings. It is higher near the wall than that in the core of the section. Increasing fluid index " $n$ ", increases fluid's viscosity and decreases Reynolds number. This results in increase of cuttings velocity and decreases cuttings slip velocities. This is clearly demonstrated in figure (8) that shows that the difference between cuttings and fluid velocities is almost zero for $n=0.8$, where $R e=967$.

\subsection{Cuttings Volume Fraction}

Cuttings volumetric fraction contours and radial velocity distributions are presented in
Figures (9)-(12). Generally, cuttings are concentrated in the middle of the annulus cross section. While, near the walls of the drill pipe and the hole, cuttings concentrations are very low. Figure (9) presents the effect of fluid consistency parameter $k_{p}$ on cuttings distribution. For fluids with small values of $k_{p}=0.01$ and $n=0.8, \quad$ [viscosity $\mu=0.0036 \quad$ Pa.s and $R e=27900]$, cuttings are concentrated in the middle of the wide section, and low cuttings concentration exists in the narrow section. For $n=0.5$, and $k_{p}=0.01$, where $R e=109600$, cuttings concentration is much higher in the wide section P3 compared to the case $\left(k_{p}=0.01\right.$ and $\left.n=0.8\right)$. Increasing $k_{p}$ to 0.1 , 1.0 and 10 , increases fluid viscosity and reduces the flow $R e$. As a result, cuttings move towards the narrow section and tend to form circular ring of high concentration region in the middle of the annulus. For the smaller flow index $n=0.5$, increasing fluid consistency $k_{p}$ results in very similar cuttings distribution development but with slower rate.

The distribution of cuttings volume fraction in the annulus flow is shown in Figure (10). It presents the effect of fluid consistency $k_{p}$ on cuttings volume fraction profiles at sections P1 and P3 for $n=0.5$. These profiles are characterized by the presence of peak in the middle of the section. Cuttings concentration in the wide section is higher than that in the narrow section of the annulus. No clear trend for the effect of fluid consistency $k_{p}$ on cuttings distribution profiles is found. 
Figure (11) shows the effect of flow index $n$ on cuttings distribution contours at $k_{p}=1.0$ and 0.1 . Results are very similar to that presented in figure (9). Cuttings are concentrated in a narrow circular ring the middle of the eccentric annulus. It exhibits higher concentration values in the wide section than in the narrow one. Increasing flow index, reduces $R e$, cuttings move towards the narrow section and tend to form circular ring of high concentration region around the drill pipe. The effect of flow index " $n$ " on cuttings volume fraction distribution profiles at sections $\mathrm{P} 1$ and $\mathrm{P} 3$ is presented in Figure (12). These profiles exhibit very sharp peak in the middle of the section, while cuttings concentration in wall region is very low. Cuttings concentration in the wide section is higher than that in the narrow section of the annulus.

\subsection{Effect of Drilling Fluid Density $\rho$}

Mud weight is one of the important properties that affect the transport of drilled cuttings. Control of mud weight is almost done by the addition of weighing material as barite to drilling fluid. The influence of drilling fluid density on the structure of cuttings and drilling fluid flow in the eccentric annulus is studied. Two fluids with $k_{p}=0.1, n=0.4$ and $k_{p}=0.3, n=0.4$ with different fluid densities $\rho=1000-1700$ $\mathrm{kg} / \mathrm{m}^{3}$ are considered. Drilling fluid and cuttings flow rates are kept constant at 10 $\mathrm{kg} / \mathrm{s}$ and $5 \mathrm{~kg} / \mathrm{s}$, giving average flow velocities varies from $2.0 \mathrm{~m} / \mathrm{s}$ for $\rho=1000$ $\mathrm{kg} / \mathrm{m}^{3}$ to $1.3 \mathrm{~m} / \mathrm{s}$ for $\rho=1700 \mathrm{~kg} / \mathrm{m}^{3}$ that corresponds to $R e=7600-6750$ for fluids with $k_{p}=0.3$ \& $n=0.4$, and
$R e=19000-17650$ for fluid with $k_{p}=0.1 \& n=0.4$.

Figures (13) present axial velocity contours and cuttings volume fraction contours for two fluid densities 1000 and $1700 \mathrm{~kg} / \mathrm{m}^{3}$. No remarkable effect of increasing fluid density on neither axial velocity contours nor cuttings distribution is detected.

Figure (14) shows the effect of density on velocity profiles of power law fluid with $k_{p}=0.3$ and $n=0.4$ at sections $\mathrm{P} 1$ and $\mathrm{P} 3$ of the eccentric annulus outlet. Profiles at each section are similar with higher velocity values for lower densities. This is due to the fact that mass flow rate are kept constant.

Figure (15a) presents comparison between the velocity of cuttings and that of carrying fluid for different fluid densities. Velocity profiles show that cuttings velocity is lower than that of fluid velocity. The difference which is known as the slip velocity is very high near the wall and very low in the core. Slip velocity is higher in the narrow section than that in the wide section. The effect is more pronounced at small densities. Figure (15b) presents the normalized slip velocity $V_{s} / U_{a v}$ as function of drilling fluid density. It shows that increasing fluid density decreases the cuttings slip velocity, hence increases the carrying capacity of drilling fluid.

\subsection{Slip Velocity of Cuttings}

The efficiencies of cuttings transport in laminar and turbulent flows are not the same. The velocity profile in turbulent flow is flatter than that in laminar flow, which is 
favorable for the prevention of cuttings falling in the outer area of the flow stream. Most investigations confirmed that turbulent flow has more effective cuttings transport capacity than laminar flow. This is mainly due to increased flow velocity. Mean fluid velocity is normally used to determine the cuttings transportability although the actual velocity distribution is not uniform across the drilling annulus [Sample and Bourgoyne (1978)].

Area weighted averaging for cuttings velocity and fluid velocity are carried out; the difference gives the average slip velocity " $V_{s}$ " at the outlet of the eccentric annulus. Figure (16a) presents the normalized slip velocity $V_{s} / U_{a v}$ as function of fluid consistency $k_{p}$. It shows that increasing $k_{p}$ increases fluids viscosity and reduces cuttings slip velocity. Results show that slip velocity are smaller for higher values of $n$. The effect of flow index " $n$ " upon the normalized slip velocity $V_{s} / U_{a v}$ is shown in Figure (16b) for $k_{p}=0.1,0.3$ and 1.0 respectively. Results show that increasing " $n$ " decreases the slip velocity of cuttings. Higher values of slip velocity are found for smaller values of fluid consistency $k_{p}$.

The effect of the two parameters $k_{p}$ and $n$ of the power law rheology model upon the slip of the cuttings flow in the eccentric annulus is combined in a single parameter. It is the drilling fluid viscosity as given by Eq. (2). All normalized slip velocity data presented in Figure (16) are plotted in Figure (17a) as function of viscosity $\mu$, and plotted as function of Reynolds number $R e$ in figure (17b). It is very interesting to find that all data are collapsed on a single curve in both figures, and to find that they are best fitted by

$$
\begin{aligned}
& V_{s} / U_{a v}=-0.05 \ln (\mu)-0.096 \\
& V_{s} / U_{a v}=0.053 \ln (R e)-0.344
\end{aligned}
$$

\subsection{Pressure Loss and Friction Coefficient}

The influence of power law fluid rheology upon the pressure loss, and friction coefficient of the two phase flow in drilling hole eccentric annulus pipes. The pressure loss gradient and coefficient inside the annulus using power law rheological model are shown in Figure (18) and 19) as function of the fluid viscosity and Reynolds number. The frictional pressure losses are predicted for cuttings size $d p=5 \mathrm{~mm}$, flow average velocity $U_{a v}=1.6 \mathrm{~m} / \mathrm{s}$, and cuttings/fluid mass ratio of $50 \%$. Results are compared with single phase flow at the same conditions.

Figure (18) presents the results of pressure loss gradient $d p / d x$ of the two phase flow of cuttings and drilling fluids in the eccentric annulus as function of drilling fluid's viscosity $\mu$ and Reynolds number $R e$. The results of the single phase flow are also presented for comparison. It is very interesting to find that all the results of the numerical experiments of the two phase flow fall on a single curve and those of the single phase flow fall in another single curve shown in figure (18). Two patterns are found, the first one is for laminar flow of high viscous fluids and low Reynolds numbers up to 10,000 , where, the gradient 
of the pressure loss increases with viscosity and decreases with Reynolds number in a power law relationship as

$$
\begin{aligned}
& \frac{d p}{d x}=C_{1} \cdot \mu^{m_{1}} \\
& \frac{d p}{d x}=C_{2} / R e^{m_{2}}
\end{aligned}
$$

The other pattern is that for low viscosity fluids and high Reynolds numbers, where the pressure gradient is almost constant. The pressure loss of two phase flow is higher than that of single phase flow.

Figure (19) presents the results of the friction coefficient $C_{f}$ of the two phase flow of cuttings and drilling fluids and the single phase flow in the eccentric annulus as function of drilling fluid's viscosity $\mu$ and Reynolds number $R e$. Similar to the results of the pressure loss $d p / d x$, all the results of the numerical experiments of the two phase flow fall on a single curve and those of the single phase flow fall in another single curve shown in figure (19). The two flow patterns are also found, where the friction coefficient $C_{f}$ for laminar flow increases with viscosity and decreases with Reynolds number in a power law relationship as

$$
\begin{aligned}
& C_{f}=C_{3} \cdot \mu^{m_{3}}, \quad \text { and } \\
& C_{f}=C_{4} / R e^{m_{4}}
\end{aligned}
$$

For low viscosity fluids and high Reynolds numbers, the friction coefficient is almost constant, and the friction coefficient $C_{f}$ of the two phase flow is higher than that of single phase flow. The difference increases with the decrease of fluid viscosity, and the increase of flow Reynolds number. The constants $C_{1}: C_{4}$ and $m_{1}: m_{4}$ are given in table (1)

\section{Conclusions}

The effect of the rheology of nonNewtonian drilling fluids on the two phase flow of drilled cuttings and drilling fluid in eccentric annulus was investigated numerically. The power law rheological model was considered and the influence of model parameters on flow structure was studied. The following are concluded:

1. Drilling fluid rheology is represented by the power law model which is characterized by two parameters; the fluid consistency " $k_{p}$ " and the flow index " $n$ ". Axial velocity contours show high velocity region in the wide section of the annulus, and low velocity region exists in the narrow section. For small values of $k_{p}$ and/or $n$, where the flow is turbulent, the high velocity region has irregular shape.

2. Increasing the values of $k_{p}$ and/or $n$, increases drilling fluid viscosity and reduces flow $R e$. As a result, the region of high velocity contours in the wide gap section becomes more regular in shape, and the velocity difference between high and low velocity regions increases.

3. When the values of $k_{p}$ and/or $n$ increase, fluid's viscosity increases, and $R e$ decreases, resulting in two velocity distribution patterns, turbulent one foi low values of $k_{p}$, and $n$ and the other is laminar for higher values of $k_{p}$ and $n$.

4. Drilling fluid velocity profiles exhibit two different types of flow regimes, 
laminar and turbulent. For small values of $k_{p}$ and/or $n$, the flow is turbulent, and the velocity distribution is almost flat with two peaks near the inside and outside walls of the annulus. For large values of $k_{p}$ and/or $n$, velocity distributions have laminar shape with peak in the middle of the section. Increasing $k_{p}$, increases the velocity in the wide section and decreases the velocity in the narrow section.

5. Cuttings slip velocity is the difference between fluid velocity " $U$ " and cuttings velocity " $U_{c}$ ". It is higher near the wall than that in the core of the section. Increasing $k_{p}$ and/or $n$ decreases the cuttings slip velocity, and decreases with the increase of drilling fluid density.

6. Slip velocity $\hat{V}_{s}$ data are found to be function of drilling fluids viscosity $\mu$, and can be best fitted by the logarithmic relationship

$$
V_{s} / U_{a v}=-0.05 \ln (\mu)-0.096
$$

7. Drilled cuttings are concentrated in circular ring in the middle of annulus, with higher volume fractions in the wide section. Regions close to the inner and outer walls of the annulus are almost free of cuttings.

8. Results of pressure loss $\mathrm{dp} / \mathrm{dx}$ and friction coefficient $C_{f}$ exhibit two patterns. The first one is for laminar flow of high viscous fluids and low Reynolds numbers up to 10,000 , where, the gradient of the pressure loss increases with viscosity and decreases with Reynolds number in power law relationship. The other pattern is that for low viscosity fluids and high Reynolds numbers, where the pressure gradient is almost constant. The pressure loss of two phase flow is higher than that of single phase flow.

\section{Nomenclature}

$C_{D} \quad$ Drag function of solid particles

$C_{f}$ Friction coefficient,

$$
C_{f}=\left[\left(\frac{d p}{d x}\right) D_{h}\right] /\left[2 \rho_{f}\left(U_{a v}\right)^{2}\right]
$$

$D_{h} \quad$ Eccentric annulus hydraulic diameter; $D_{h}=\left(D_{o}-D_{i}\right) ;(\mathrm{m})$

$D_{i} \quad$ Inner diameter of the eccentric annulus

$D_{o}$. Outer diameter of the eccentric annulus

$d p \quad$ Cuttings particle size $(\mathrm{mm})$

$d p / d x \quad$ Pressure loss gradient $(\mathrm{Pa} / \mathrm{m})$

$D_{s}$ and $D_{f}$ Solid and liquid diffusivities,

$d_{s}$ Diameter of solid particles phase

e eccentricity of the eccentric annulus $(\mathrm{mm})$

$e_{s s}$ Coefficient of restitution for particle collisions $\left(e_{s s}=0.9\right.$ ),

$\vec{F}_{f} \quad$ External body force for liquid phase,

$\vec{F}_{S} \quad$ External body force for solid phase,

$\vec{F}_{l i f t, f}$ Lift force for liquid phase,

$\vec{F}_{l i f t, s} \quad$ Lift force for solid phase,

$\vec{F}_{v m, f}$ The virtual mass force for liquid phase,

$\vec{F}_{v m, s}$ The virtual mass force for solid phase,

$G_{k, f}$ Production of turbulent kinetic energy.

$g_{0}$. Radial distributions function; $g_{0, s s}$ is that for particle collisions

$I_{2 D} \quad$ Second invariant of the deviatoric stress tensor.

$k_{f} \quad$ Turbulent kinetic energy of liquid phase

$K_{f s} \quad$ Solid-fluid momentum exchange coefficient

$k_{p} \quad$ Power law model fluid consistency $\left(\mathrm{Pa} . \mathrm{s}^{\mathrm{n}}\right)$

$K_{s f} \quad$ Fluid-solid momentum exchange coefficient

$L \quad$ Length of the eccentric annular passage

$L_{t, f} \quad$ Characteristic length scales of turbulent eddies

$\dot{m}_{p q}$ Mass transfer from the $p$ to $q$ phase, $\sum_{p=1}^{n} \dot{m}_{p q}=0$

$m_{r} \quad$ Cuttings to drilling fluid mass ratio

$n \quad$ Power law model flow index

$p \quad$ Pressure shared by all phases 
$p_{s} \quad$ Solids phase pressure,

Re Flow Reynolds number based on drilling fluid parameters, $\operatorname{Re}=\left(\rho_{f} \cdot U_{a v} \cdot D_{h}\right) / \mu_{f}$

$R e_{s}$ The relative Reynolds number; $R e_{s}=$ $\frac{\rho_{f} d_{s}\left|\vec{U}_{s}-\vec{U}_{f}\right|}{\mu_{f}}$

$r_{n} \quad$ Normalized radial distance $r_{n}$ defined as: $r_{n}=\left(r-r_{\min }\right) /\left(r_{\max }-r_{\min }\right)$

$T_{f}^{\prime} \quad$ Reynolds stress tensor for continuous phase " $f$ " takes the following form:

$T_{q} \quad$ Stress-strain tensor of the liquid phase "f" and solid phase "s"

$u \quad$ Fluid flow velocity $(\mathrm{m} / \mathrm{s})$

$U_{a v} \quad$ Average drilling fluid flow velocity $(\mathrm{m} / \mathrm{s})$

$U_{c} \quad$ Average cuttings velocity $(\mathrm{m} / \mathrm{s})$

$u_{c} \quad$ Cuttings velocity $(\mathrm{m} / \mathrm{s})$

$\vec{U}_{d r} \quad$ Drift velocity and is given by

$\vec{U}_{f} \quad$ The velocity of drilling fluid phase

$\vec{U}_{q} \quad$ The velocity of phase $q$

$\vec{U}_{s} \quad$ The velocity of cuttings solid phase $q$

$\vec{U}_{s f} \quad$ Solid - fluid relative velocity,

$V_{s} \quad$ Average cuttings slip velocity, $V_{s}=\left(U_{a v}-U_{c}\right)(\mathrm{m} / \mathrm{s})$

$v_{s} \quad$ Cuttings slip velocity, $v_{s}=\left(u-u_{c}\right)$ $(\mathrm{m} / \mathrm{s})$

\section{Greek Symbols}

$\alpha_{f} \quad$ Volumetric fraction of the fluid phase

$\alpha_{s} \quad$ Volumetric fraction of solid phase

$\varepsilon_{f} \quad$ Dissipation rate of turbulence of liquid phase

$\phi \quad$ exchange-coefficient function

$\gamma \quad$ Strain rate,

$\lambda_{s} \quad$ Solids bulk viscosity

$\mu_{s, c o l}$ Collision part of solids shear viscosity

$\mu_{s, f r} \quad$ Friction of solids shear viscosity

$\mu_{s, k i n}$ Kinetic part of solids shear viscosity

$\mu_{s} \quad$ Solids shear viscosity

$\mu_{t, f} \quad$ Turbulent viscosity of liquid phase

$\theta \quad$ Angle of internal friction,

$\tau \quad$ Shear stress,

$\tau_{s} \quad$ Solid particles relaxation time

$\tau_{t, f}$ Characteristic time scale of turbulent eddies

$\Pi_{k, f}$ Influence of the dispersed phase on the liquid phase $f$, in $k \mathrm{Eq}$. of the $k-\varepsilon$ model.

$\Pi_{\varepsilon, f}$ Influence of the dispersed phases on the liquid phase $f$, in $\varepsilon$ Eq. of the $k-\varepsilon$ model.
$\Theta_{S} \quad$ Granular temperature due to kinetic energy of the fluctuating particle motion.

$\Omega \quad$ Drill pipe rotation (rpm).

\section{References}

- Amundarain, J. L., Castro, L. J., Rojas, M. R., Siquier, S., Ramírez, N., Müller, A. J., and Sáez, A. E., "Solutions of Xanthan gum/guar gum mixtures: shear rheology, porous media flow, and solids transport in annular flow", Rheol Acta (2009) 48:491498

- Azar, J. J. and Sanchez, R.A., "Important Issues in Cuttings Transport for Drilling Directional Wells," SPE Paper 39020 presented at the $5^{\text {th }}$ Latin America and Caribbean Petroleum Engineering Conference, Rio de Janeiro, Brazil, Aug. 30 Sept. 3, (1997).

- Azouz, I., Shirazi, S. A., Pilehvari A., and Azar J. J., "Numerical Simulation of Laminar Flow of Yield Power Law Fluids in Conduits of Arbitrary Cross Section", Transactions of the ASME, Journal of Fluids Engineering, 115(4):710-716, Dec. (1993).

- Brown N. P., Bern P. A., and Weaver A., "Cleaning Deviated Holes: New Experimental and Theoretical Studies", Proceedings of the SPE/IADC Drilling Conference, p171-180, (1989).

- Fluent, User's Guide FLUENT 6.3.26. Fluent Inc., Canonsburg, PA, (2006).

- Gambit User's Guide GAMBIT 2.3.16. Fluent Inc., Canonsburg, PA, (2006).

- Gidaspow, D., Bezburuah, R. and Ding, J., Hydrodynamics of Circulating Fluidized Beds, Kinetic Theory Approach., In Fluidization VII, Proceedings of the $7^{\text {th }}$ Engineering Foundation Conference on Fluidization, pages 75-82, (1992).

- Haciislamoglu, M., "Non-Newtonian Flow in Eccentric Annuli and its Application to Petroleum Engineering Problems", Ph.D. Dissertation, Louisiana State University, Baton Rouge, Louisiana, (1989).

- Hemphill, T., and Larsen, T. I., "HoleCleaning Capabilities of Oil-Based and Water-Based Drilling Fluids: A Comparative Experimental Study", SPE 26328, presented at the $65^{\text {th }}$ Annual Technical Conference and Exhibition, Houston-Texas (October 3-6, (1993)) 
- Hopkin, E. A., "Factors Affecting Cuttings Removal during Rotary Drilling," paper SPE 1697 presented at the SPE-AIME 45th Annual Fall Meeting, Houston (Oct. 1970).

- Launder B. E., and Spalding. D. B., "The Numerical Computation of Turbulent Flows", Computer Methods in Applied Mechanics and Engineering, 3, 269-289, (1974).

- Lauzon, R. V., and Reid, K. I. B, "New Rheological Model Offers Field Alternative", Oil and Gas J. 77, pp 51-57 (May 21, 1979).

- Lun, C. K., Savage, S. B., Jeffrey, D. J., and Chepurniy, N., "Kinetic Theories for Granular Flow: Inelastic Particles in Couette Flow and Slightly Inelastic Particles in a General Flow Field", J. Fluid Mech., 140, 223-256, (1984).

- Mitsuishi, N., and Aoyagi, Y., "NonNewtonian Fluid Flow in an Eccentric Annulus," J. Chem. Eng. Japan 6, 402-408, (1973).

- Newitt, D. M., Richardson, J. F., and Gliddon, B. J., "Hydraulic Conveying of Solids in Vertical Pipes," Trans., Inst. Chem. Eng. 39, pp 93-100 (1961).

- Ogawa, S., Umemura, A., and N. Oshima. N., "On the Equation of Fully Fluidized Granular Materials", J. Appl. Math. Phys., 31:483, (1980).

- Okrajni, S. S. and Azar, J. J., "The Effects of Mud Rheology on Annular Hole Cleaning in Directional Wells", SPE D.E., 14178-PA, pp.297-308, Aug. (1986).

- Pérez, R. M. Siquier, S. Ramírez, N., Müller, A. J., and Sáez, A. E., "Non-Newtonian Annular Vertical Flow of Sand Suspensions in Aqueous Solutions of Guar Gum", Journal of Petroleum Science and Engineering, Volume 44, Issues 3-4, Pages 317-331, 15 November (2004).

- Pigott, R. J. S., "Mud Flow in Drilling", Drilling and Production Proceeding, API, pp. 91-103, (1941).

- Sakr, M. L. H., "Turbulent Flow of NonNewtonian Drilling Fluids in Eccentric Annular Channels", M.Sc. thesis, Mansoura University, Mansoura, Egypt (2008)

- Sample, K. J., and Bourgoyne, A T., "Development of Improved Laboratory and Field Procedures for Determining the Carrying Capacity of Drilling Fluids," SPE
Paper 7497 presented at the $53^{\text {rd }}$ Annual Fall Technical Conference, Houston, Texas, Oct. 1-3, (1978).

- Sample, K. J. and Bourgoyne, A T., "An Experimental Evaluation of Correlations Used for Predicting Cutting Slip Velocity," SPE Paper 6645 presented at the $52^{\text {nd }}$ Annual Fall Technical Conference, Denver, Colorado, Oct. 9-12, (1977).

- Sanchez, R.A., Azar, J.J., Bassal, A.A. and Martins, A.L., "Effect of Drillpipe Rotation on Hole Cleaning During Directional-Well Drilling", SPEJ, pp. 101-107, June (1999).

- Schaeffer, D. G., "Instability in the Evolution Equations Describing Incompressible Granular Flow", J. Diff. Eq., 66, 19-50, (1987).

- Simonin, C., and Viollet, P. L., "Predictions of Oxygen Droplet Pulverization in a Compressible Subsonic Co-flowing Hydrogen Flow", Numerical Methods for Multiphase Flows, FED91, pp 65-82, (1990).

- Syamlal, M., Rogers, W., and O'Brien, T. J., MFIX Documentation, Theory Guide., National Technical Information Service, Springfield, VA, (1993). DOE/METC-94/1004.

- Tomren, P. H., lyoho, A. W. and Azar, J. J., "An Experimental Study of Cuttings Transport in Directional Wells", SPE DE, pp. 43-56, Feb. (1986).

- Vinod, P. S., "Effect of Fluid Rheology on Hole Cleaning in Highly-Deviated Wells", PhD thesis, RICE University, Houston, Texas June, (1994)

- Wang, Z., Guo, X., Li, M., Hong, Y., "Effect of Drilling Rotation on Borehole Cleaning for Extended Reach Well", Journal of Hydrodynamics, 21(3), pp. 366-372, (2009).

- Williams, C. E., and Bruce, G. H., "Carrying Capacity of Drilling Muds", Trans. AIME 192, pp. 111-120, (1951).

\section{Table (1)}

Constants of the pressure gradient and friction coefficient power law relations $C_{1}: C_{4}$ and $m_{1}: m_{4}$

\begin{tabular}{|l|c|c|c|c|}
\hline \multicolumn{1}{|c|}{ Flow Type } & $C_{1}$ & $C_{2}$ & $C_{3}$ & $C_{4}$ \\
\hline Single phase & 0.22 & 2300 & 0.002 & 20 \\
\hline Two phase & 0.80 & 660 & 0.007 & 5.5 \\
\hline & $m_{1}$ & $m_{2}$ & $m_{3}$ & $m_{4}$ \\
\hline Single phase & 0.82 & 0.82 & 0.82 & 0.82 \\
\hline Two phase & 0.65 & 0.55 & 0.65 & 0.55 \\
\hline
\end{tabular}




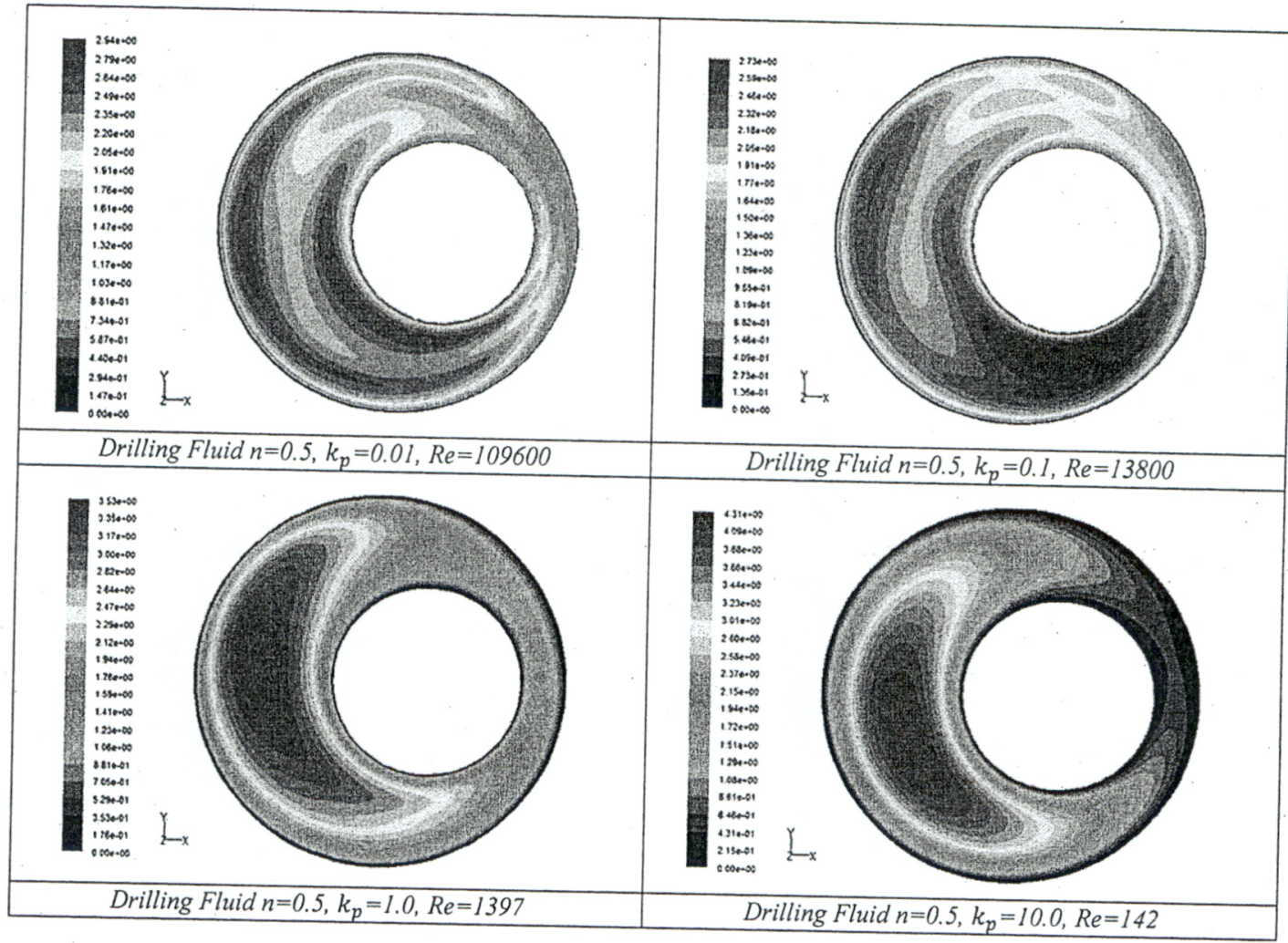

Figure (3): Axial velocity contours of power law drilling fluids with different fluid consistency $k_{p}$, and constant flow index $n=0.5$, in eccentric annulus $U_{a v}=2.0 \mathrm{~m} / \mathrm{s}$, and $m_{r}=50 \%, d p=5 \mathrm{~mm}$.

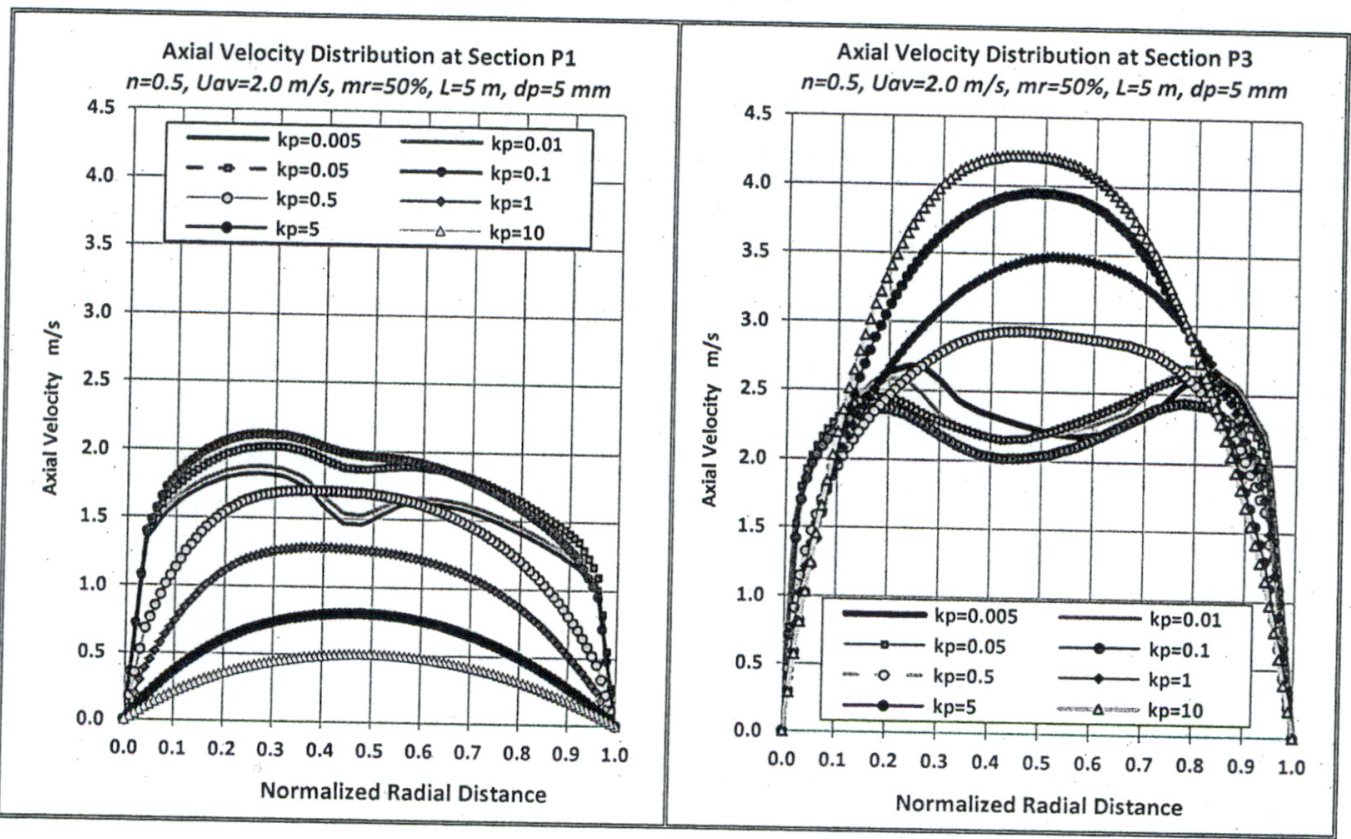

Figure (4)

Axial velocity profiles of power law fluid with different fluid consistency $k p$ and constant flow index $n=0.5$, in eccentric annulus, $L=5 \mathrm{~m} \cdot U_{a v}=2.0 \mathrm{~m} / \mathrm{s}$, and $m_{r}=50 \%, d p=5 \mathrm{~mm}$. 


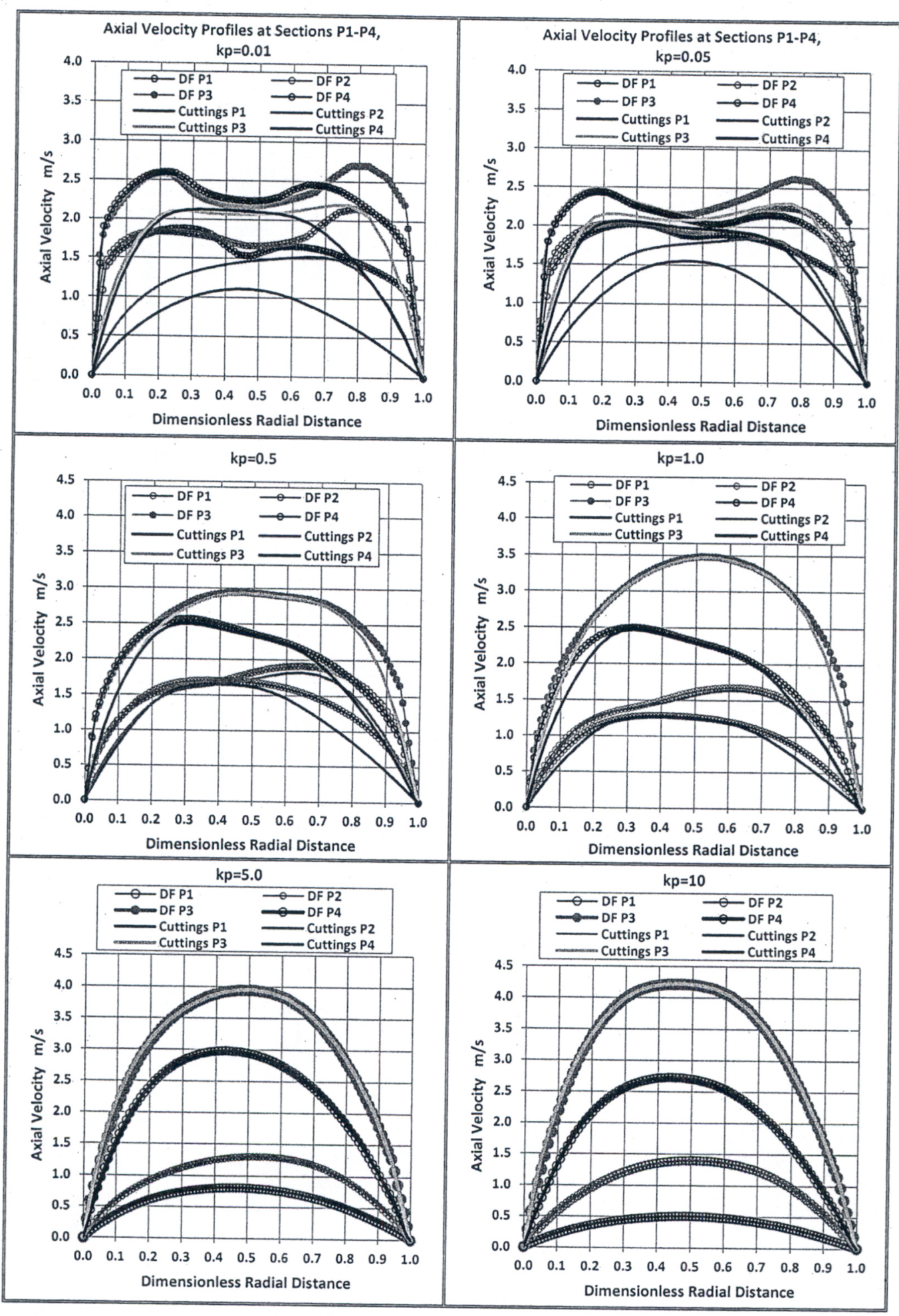

Figure (5): Cuttings velocity profiles and drilling fluids velocity profiles of power law fluids with different fluid consistencies $k_{p}$ and constant flow index $n=0.5$, in eccentric annulus, $U_{a v}=2.0 \mathrm{~m} / \mathrm{s}$, and $m_{r}=50 \%$. 


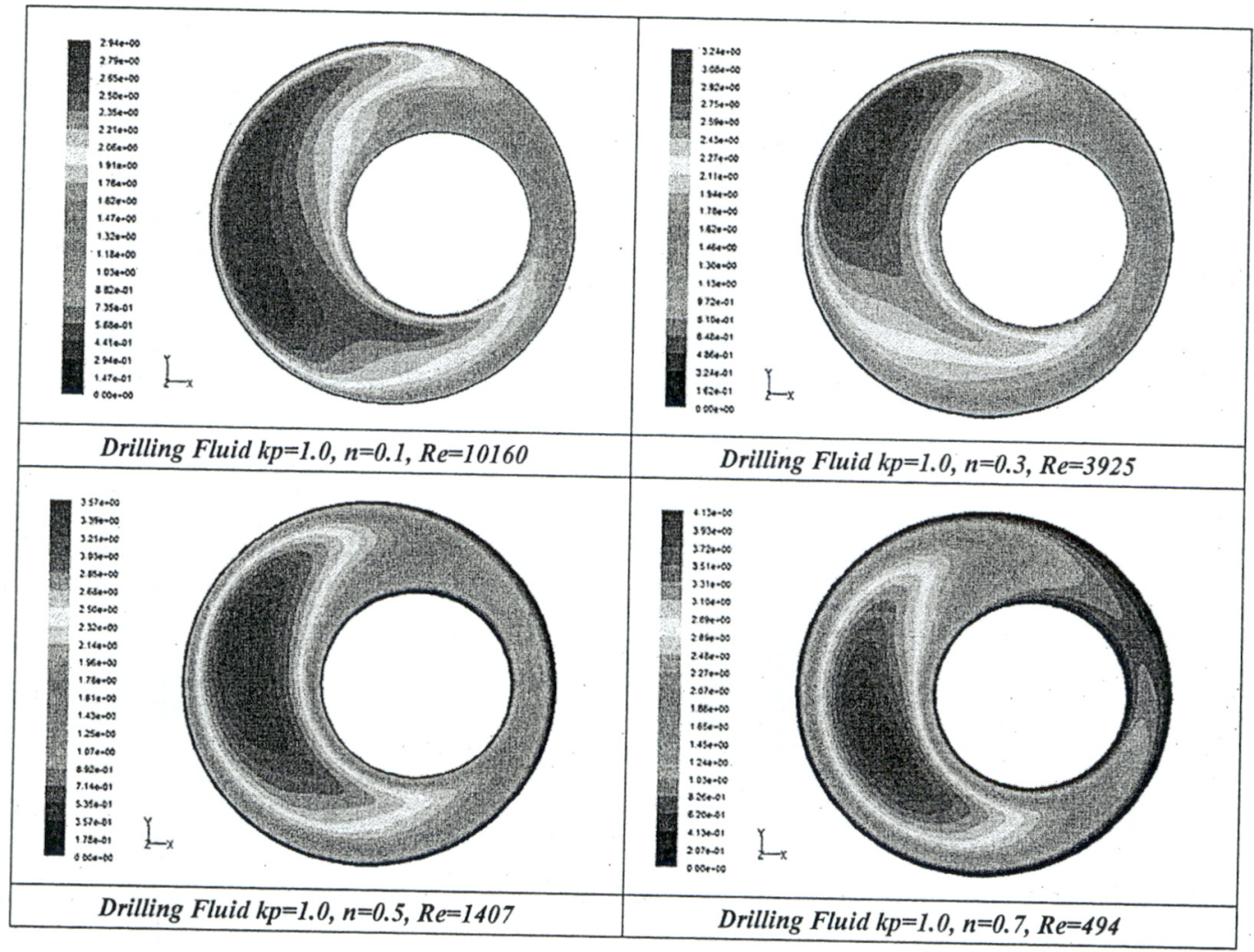

Figure (6): Axial velocity contours of power law drilling fluids with different flow index $n$, and constant fluid consistency $k_{p}=1.0$, in eccentric annulus, $U_{a v}=2.0 \mathrm{~m} / \mathrm{s}$, and $m_{r}=50 \%$.

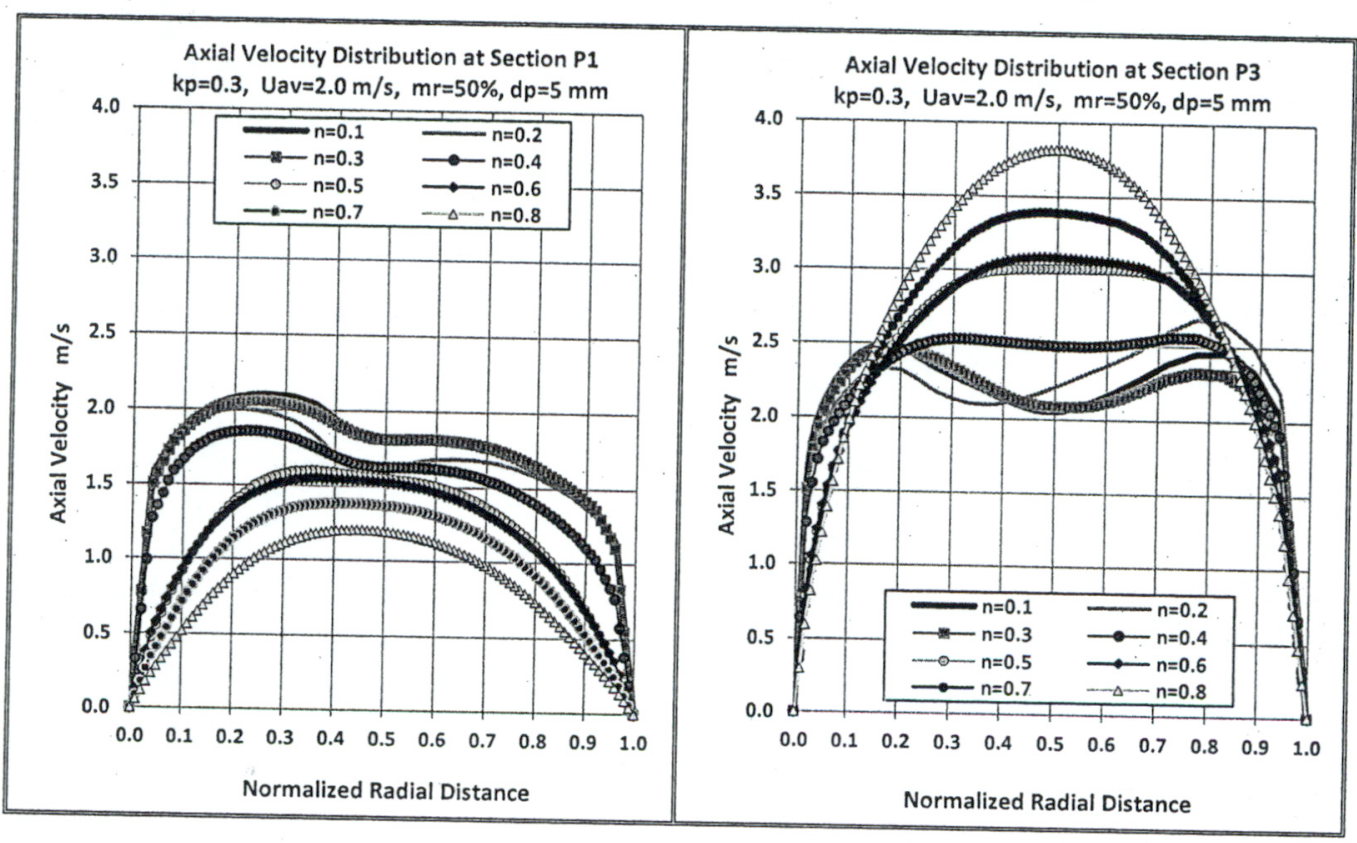

Figure (7): Axial velocity profiles of power law fluids with different flow index " $n$ " and $k_{p}=0.3$ in eccentric annulus, $L=5 \mathrm{~m}, U_{a v}=2.0 \mathrm{~m} / \mathrm{s}$, and $m_{r}=50 \%, d p=5 \mathrm{~mm}$ 


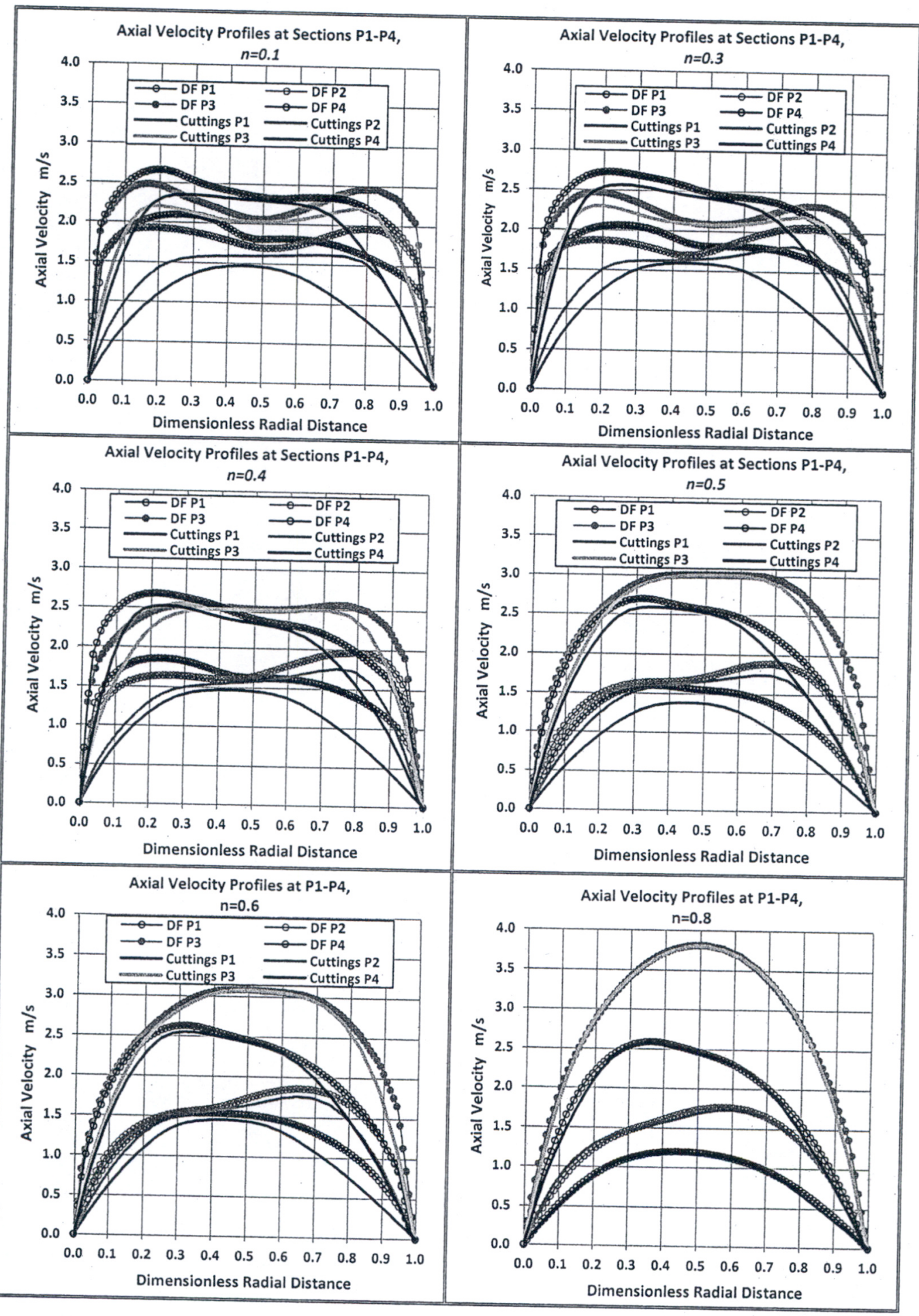

Figure (8): Cuttings and Drilling Fluids axial velocity profiles for different flow indices " $n$ " and constant fluid consistency $k_{p}=0.3$, for the flow in eccentric annulus $U_{a v}=2.0 \mathrm{~m} / \mathrm{s}$, and $m_{r}=50 \%, d p=5 \mathrm{~mm}$. 
M. 24 Mohamed L. H. Sakr, A. A. Sultan, M. A. Tolba and M. A. Badawy

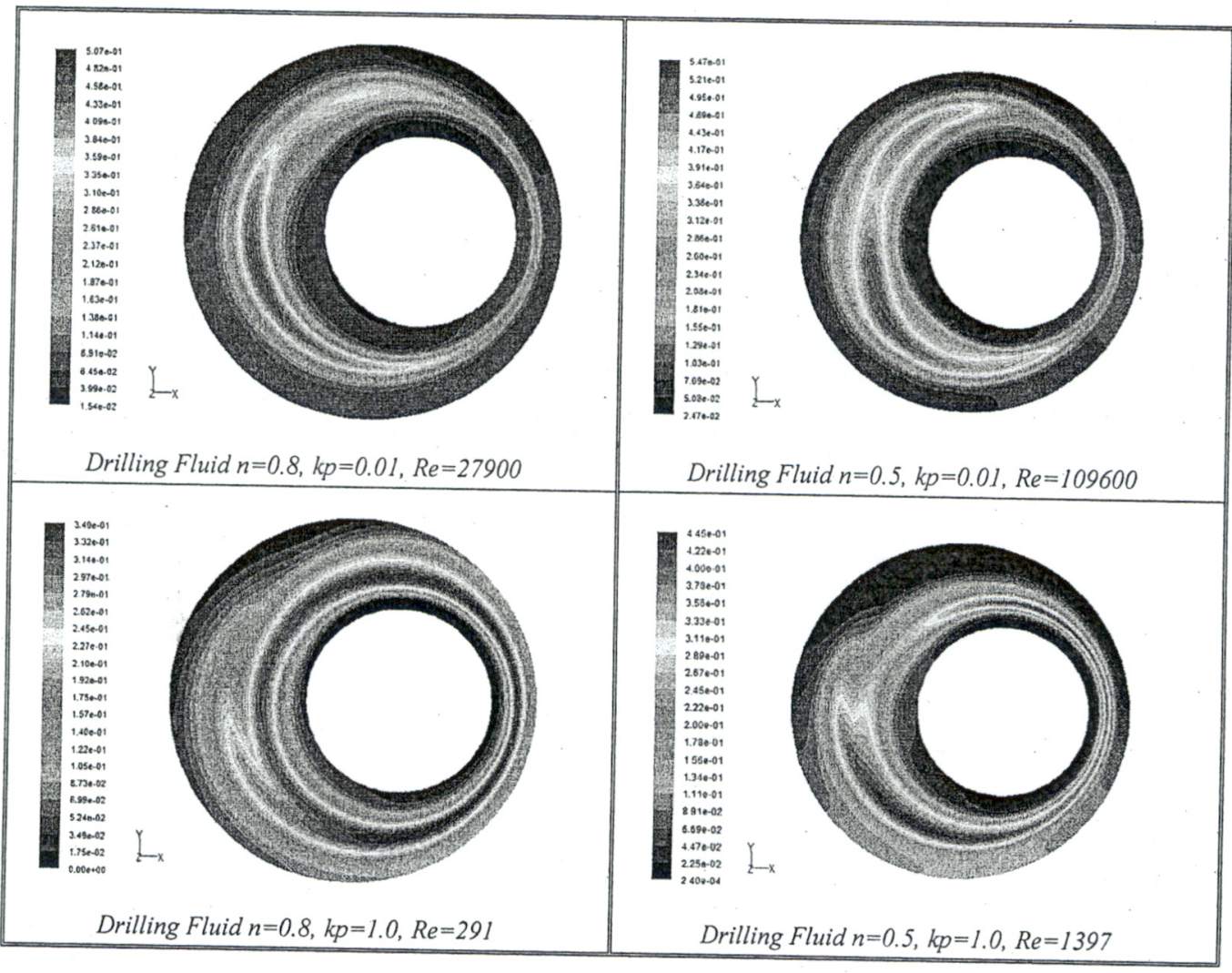

Figure (9): Cuttings volume fraction contours for drilling fluids with different fluid consistencies $k_{p}$, flow index $n=0.8$ and $0.5, U_{a v}=2.0 \mathrm{~m} / \mathrm{s}$, and $m_{r}=50 \%$.

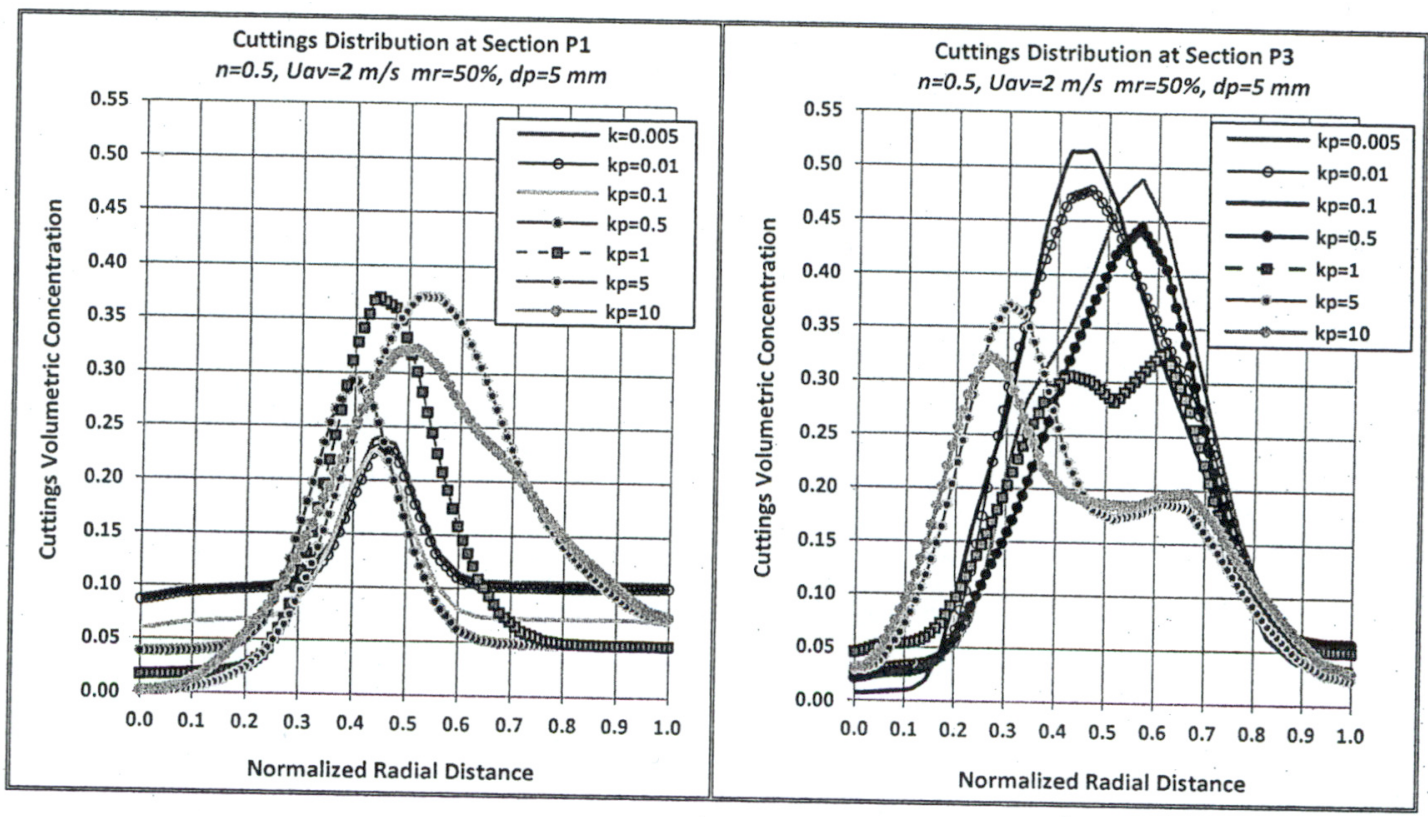

Figure (10): Cuttings volume fraction profiles in eccentric annulus flow of power law fluid with different fluid consistencies $k_{p}$ and flow index $n=0.5, U_{a v}=2.0 \mathrm{~m} / \mathrm{s}$, and $m_{r}=50 \%$. 


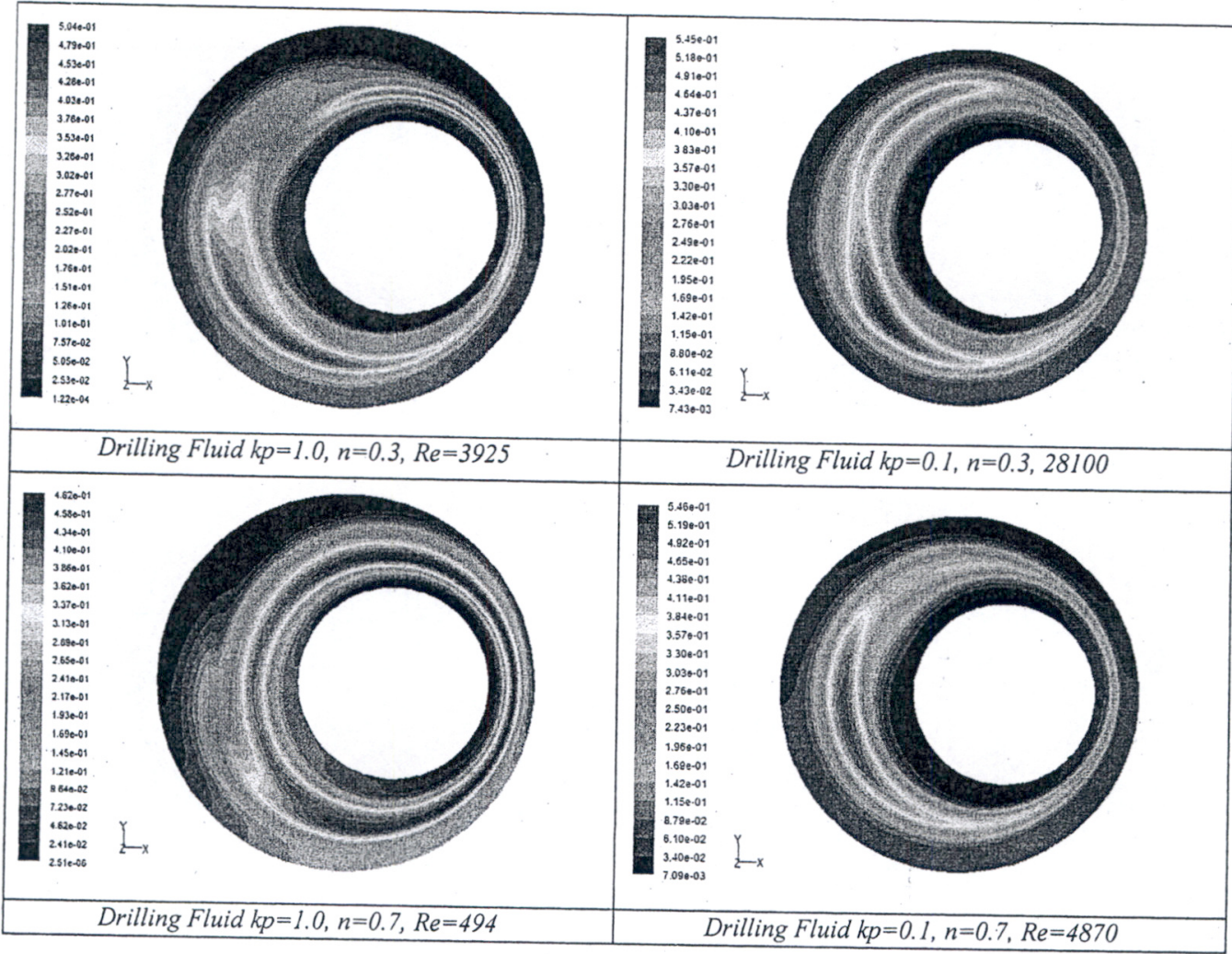

Figure (11): Cuttings volume fraction contours of power law drilling fluids with different flow indices $n$, fluid consistency $k_{p}=1.0$ and $0.1, U_{a v}=2.0 \mathrm{~m} / \mathrm{s}$, and $m_{r}=50 \%, d p=5 \mathrm{~mm}$.

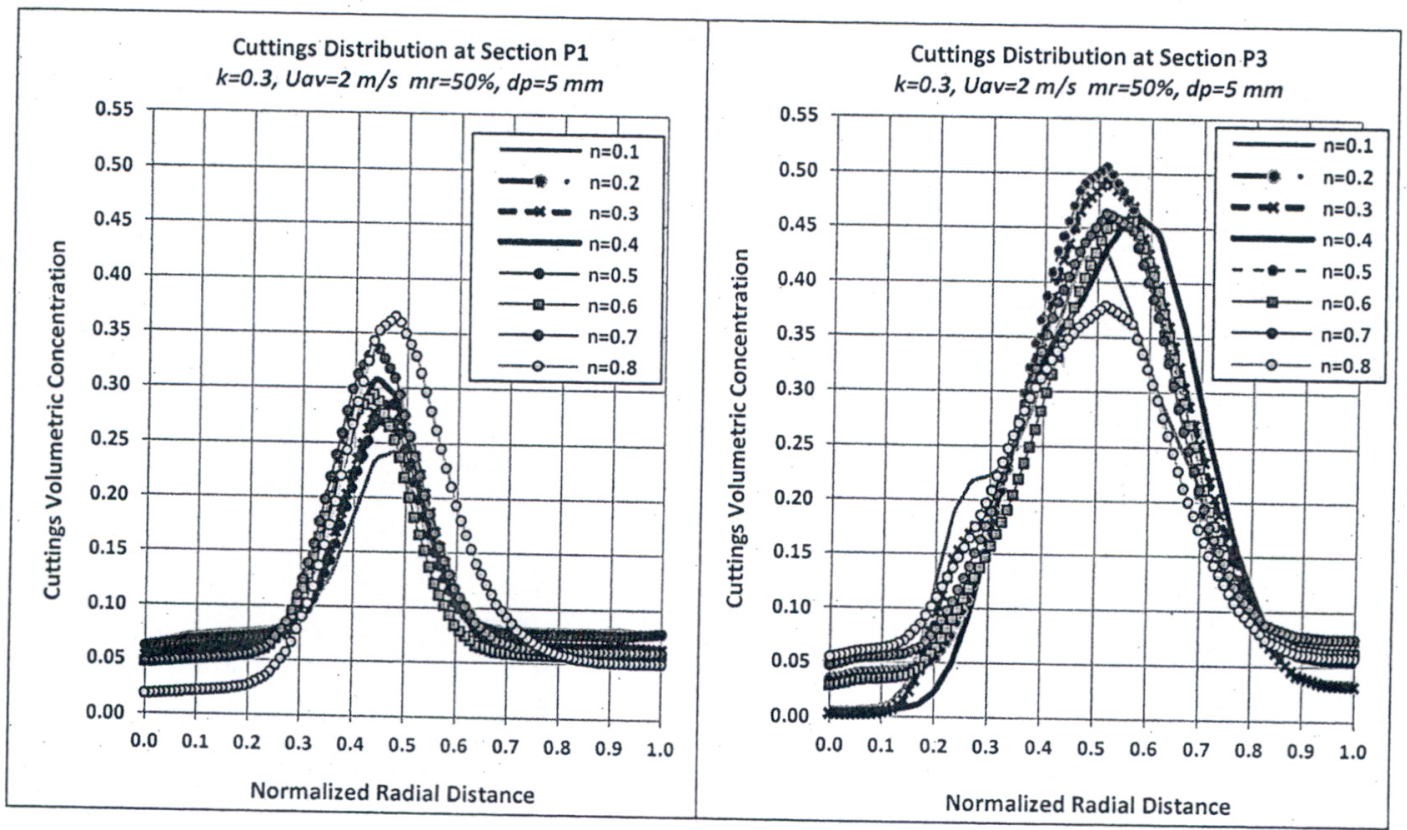

Figure (12): Cuttings volume fraction profiles for power law fluid with different flow indices " $n$ " and constant $k_{p}=0.3$, flow in eccentric annulus, $U_{a v}=2.0 \mathrm{~m} / \mathrm{s}$, and $m_{r}=50 \%, d p=5 \mathrm{~mm}$. 
M. 26 Mohamed L. H. Sakr, A. A. Sultan, M. A. Tolba and M. A. Badawy

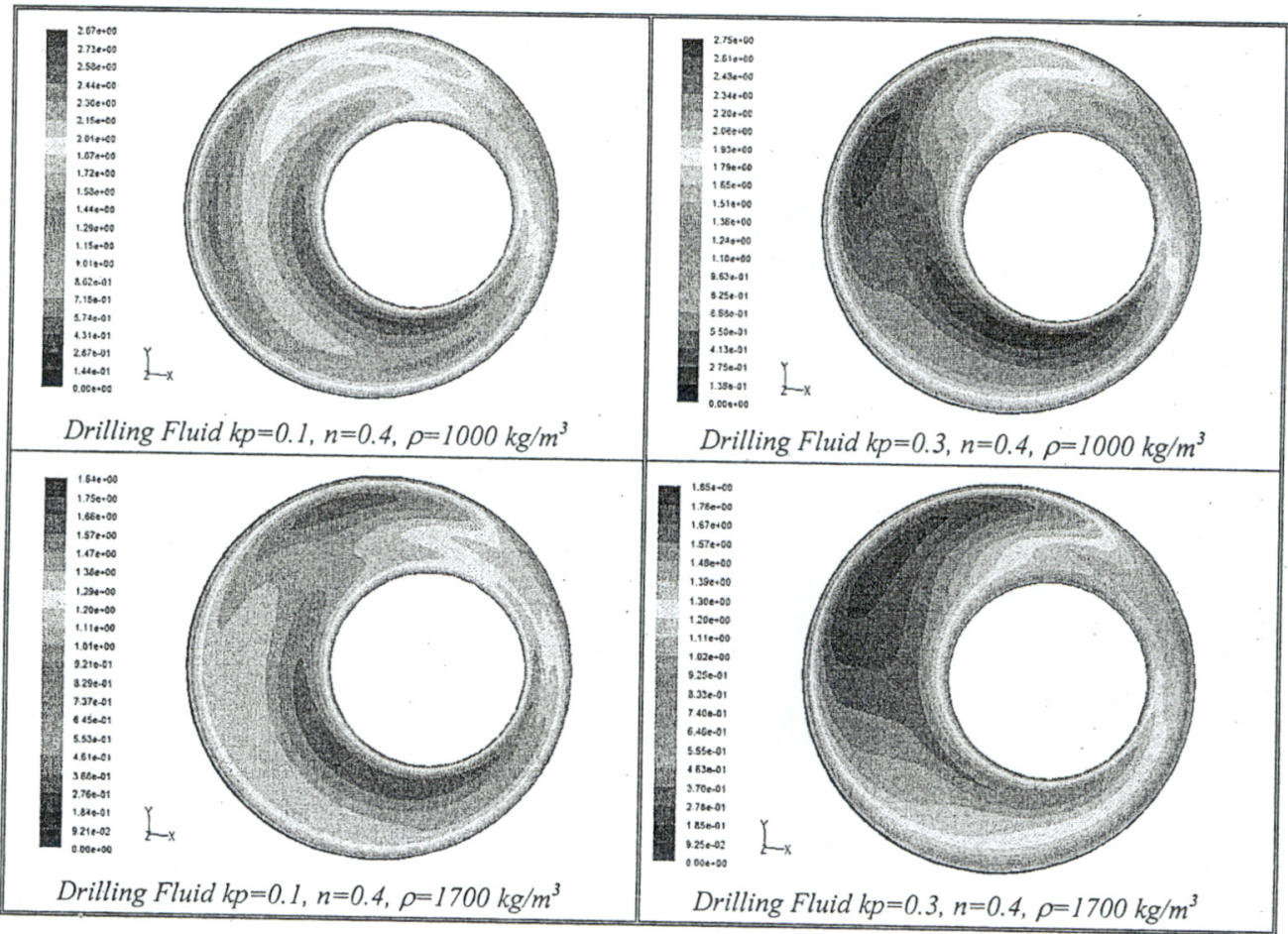

Figure (13-a): Fluid flow velocity contours of power law drilling fluid with different densities, $k_{p}=0.1 \&$ $n=0.4$, and $k_{p}=0.3 \& n=0.4, U_{a v}=2.0 \mathrm{~m} / \mathrm{s}, m_{r}=50 \%$, and $d p=5 \mathrm{~mm}$.

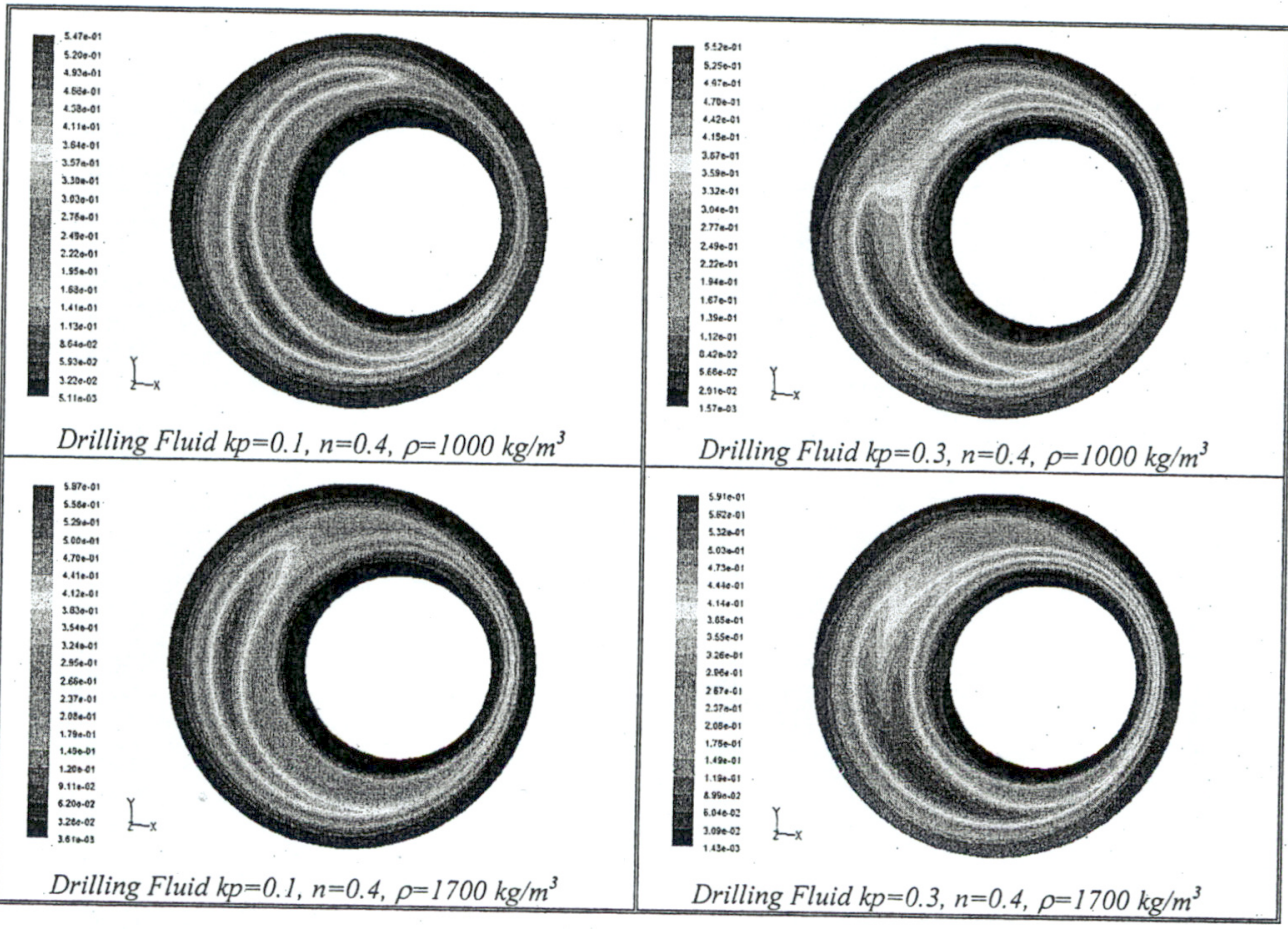

Figure (13-b): Cuttings volume fraction contours of power law drilling fluid with different densities, $k_{p}=0.1 \& n=0.4$, and $k_{p}=0.3 \& n=0.4, U_{a v}=2.0 \mathrm{~m} / \mathrm{s}$, and $m_{r}=50 \%, d p=5 \mathrm{~mm}$. 


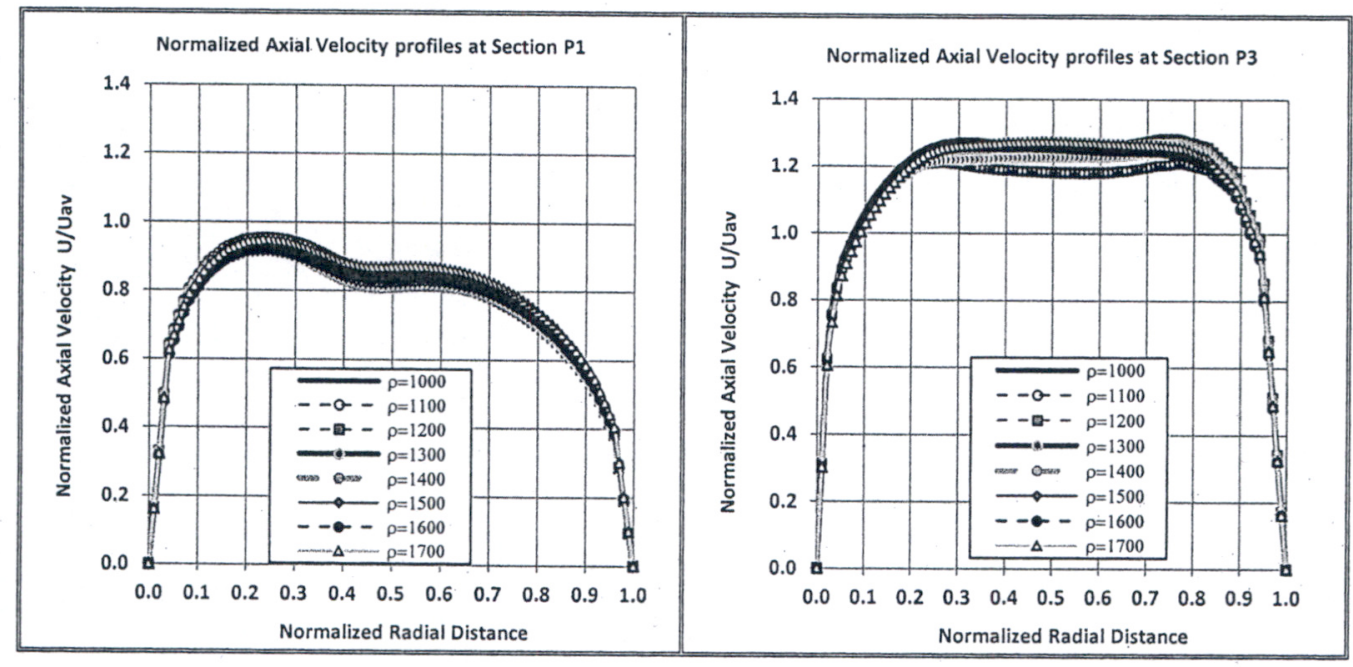

Figure (14): Effect of fluid density on axial velocity profiles of power law fluid $(n=0.4$ and $k p=0.3$ ) for flow in the eccentric annulus, $L=5 \mathrm{~m}, U_{a v}=2.0 \mathrm{~m} / \mathrm{s}, m_{r}=50 \%, d p=5 \mathrm{~mm}$

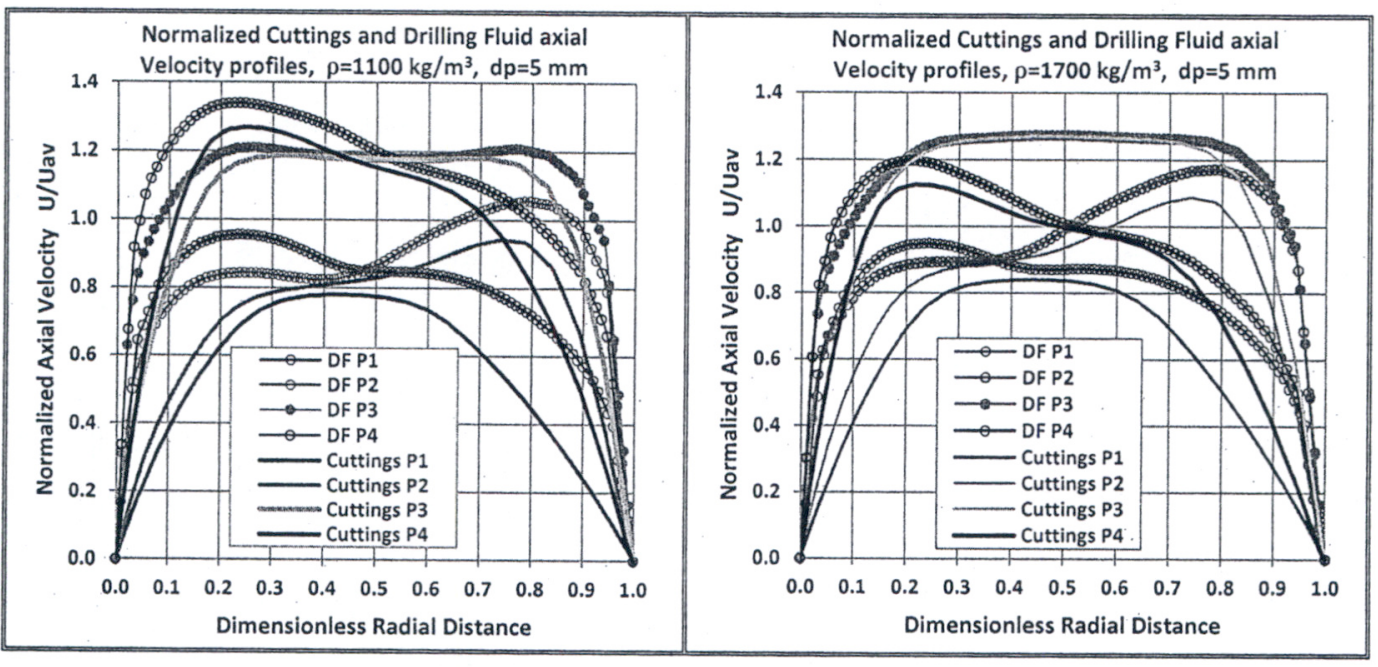

Figure (15-a): Effect of fluid density on cuttings and drilling fluids velocity profiles of power law fluid $(n=0.4$ and $k=0.3)$ for the flow in the eccentric annulus, $L=5 \mathrm{~m}, U_{a v}=2.0 \mathrm{~m} / \mathrm{s}, m_{r}=50 \%, d p=5 \mathrm{~mm}$

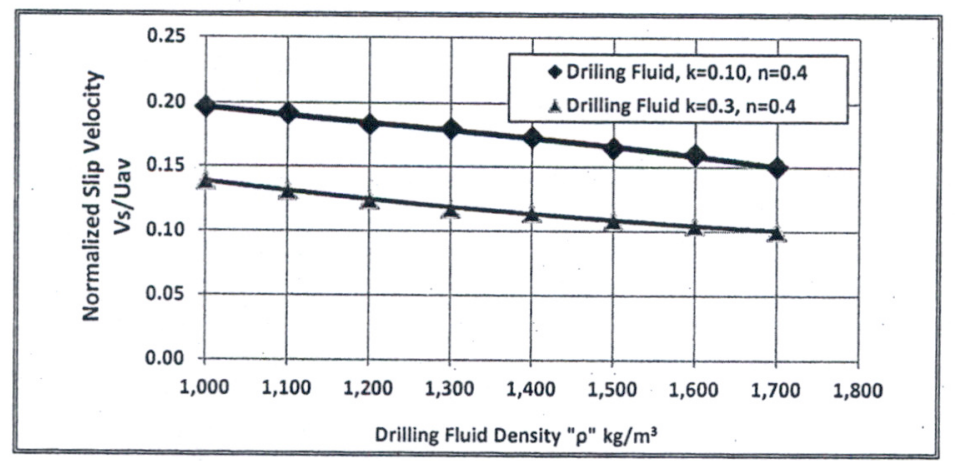

Figure (15-b): Effect of drilling fluid's density $\rho$ on cuttings normalized slip velocity 


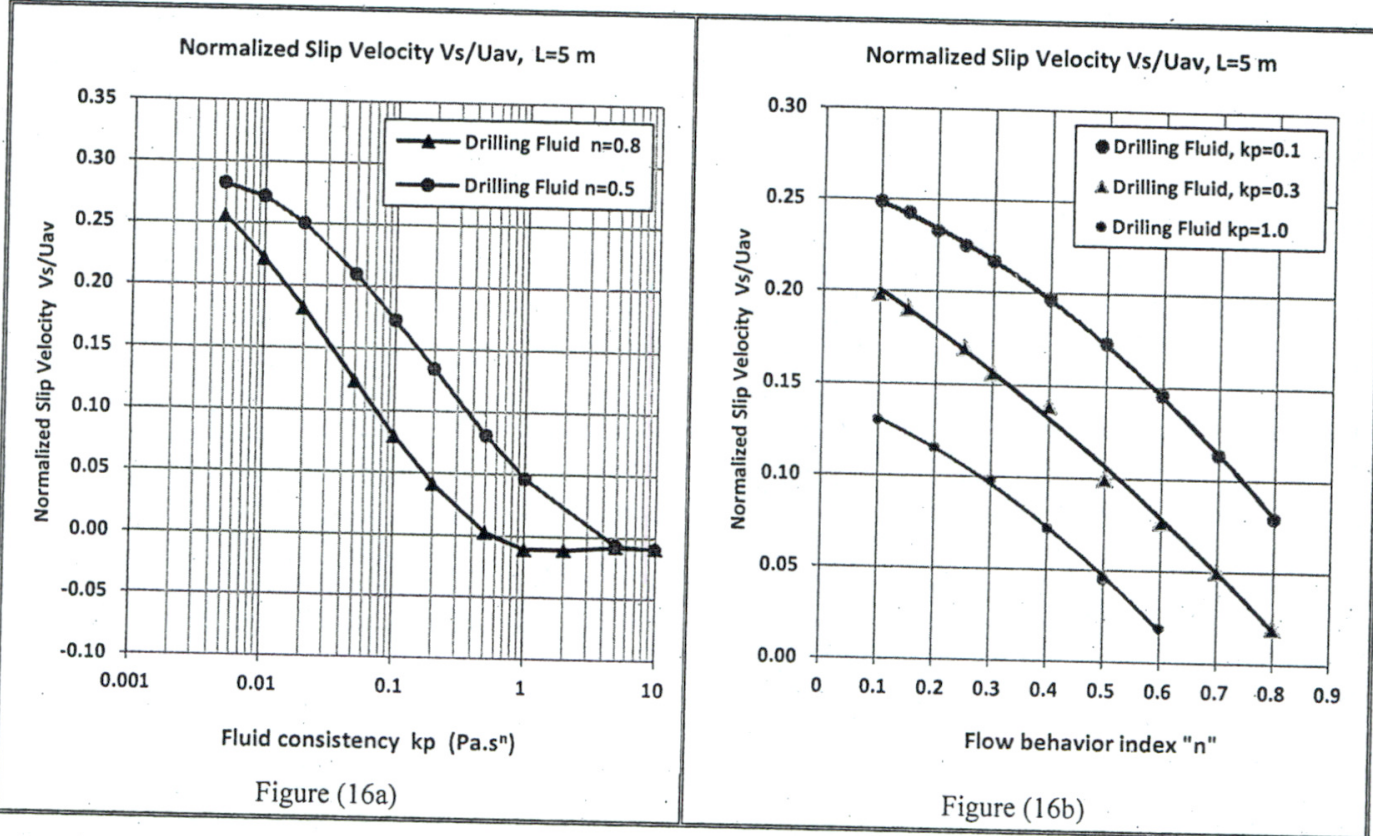

Figure (16): The effect of parameters $k$ and $n$ of the power law rheology model upon normalized slip velocity of the cuttings in the eccentric annulus, $L=5 \mathrm{~m}, U_{a v}=2.0 \mathrm{~m} / \mathrm{s}, m r=50 \%, d p=5 \mathrm{~mm}$.

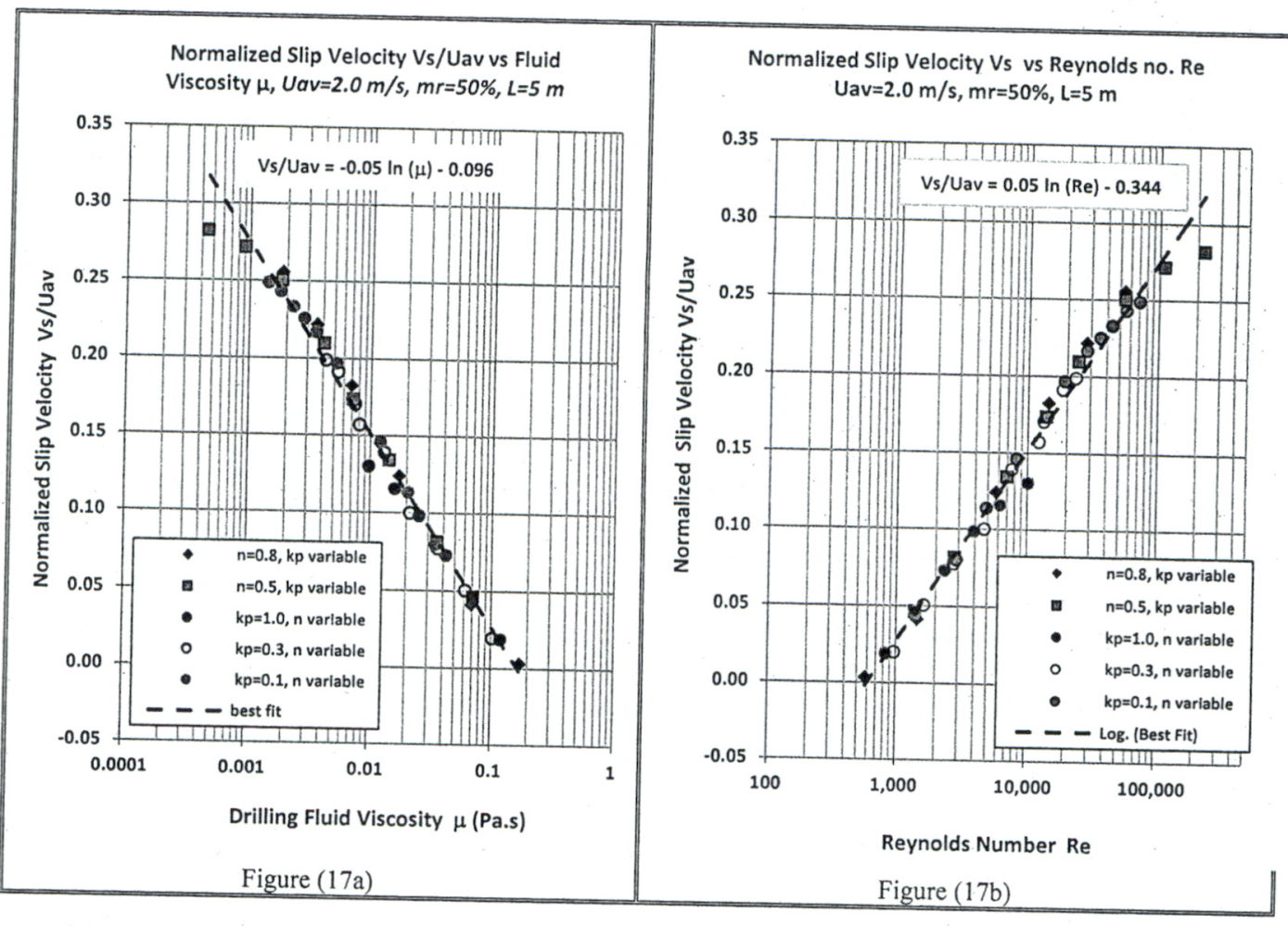

Figure (17): The effect of drilling fluid's viscosity $\mu$, and Reynolds number Re upon the normalized slip velocity of the cuttings in the eccentric annulus, $L=5 \mathrm{~m}, U_{a v}=2.0 \mathrm{~m} / \mathrm{s}, m r=50 \%, d p=5 \mathrm{~mm}$. 


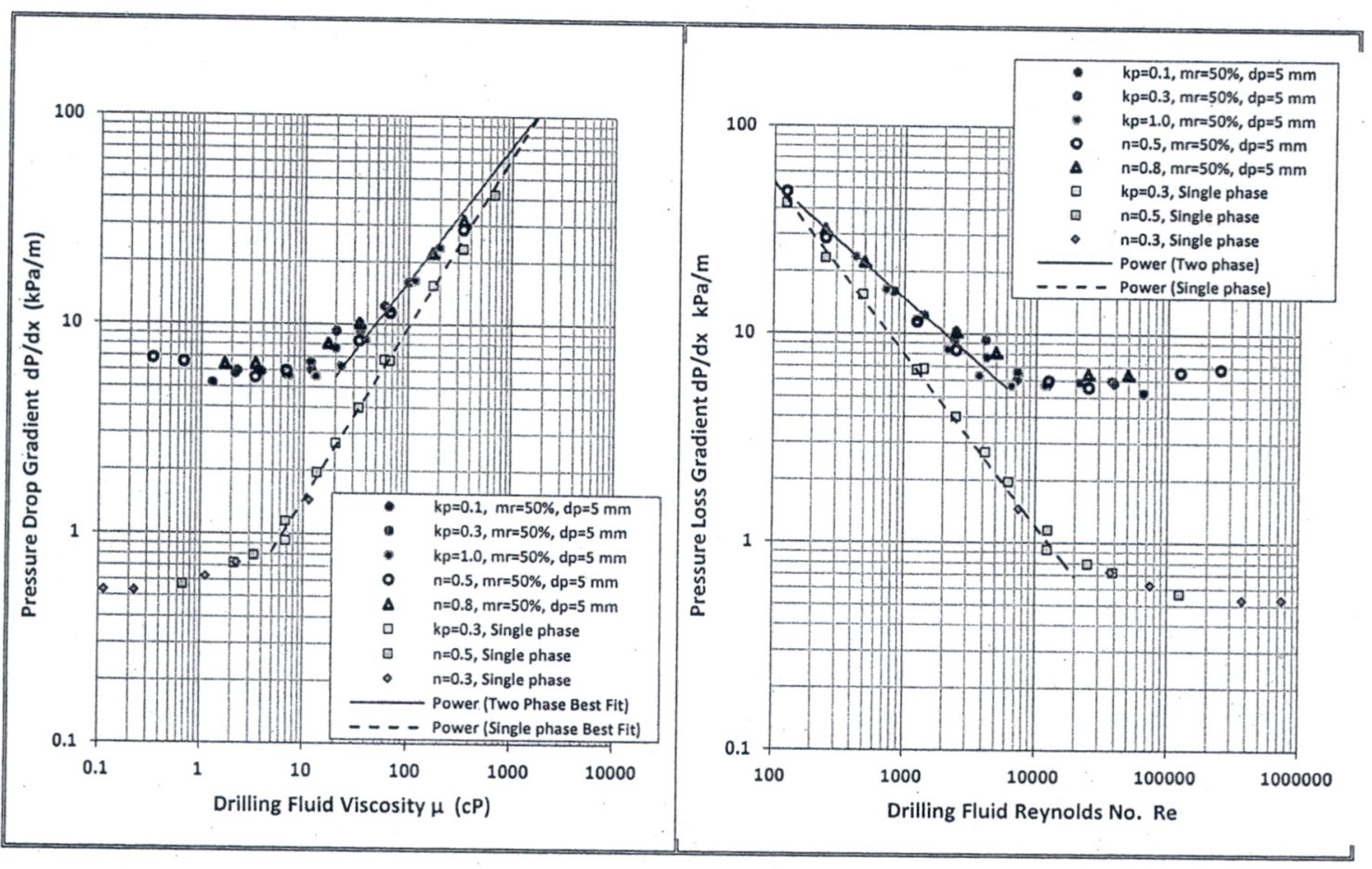

Figure (18): Effect of drilling fluid viscosity $\mu$, and Reynolds number $R e$ on the gradient of pressure drop $d P / d x$ of the single phase and two phase flows, $L=5 \mathrm{~m}, U_{a v}=1.6 \mathrm{~m} / \mathrm{s}, m r=50 \%, d p=5 \mathrm{~mm}$.

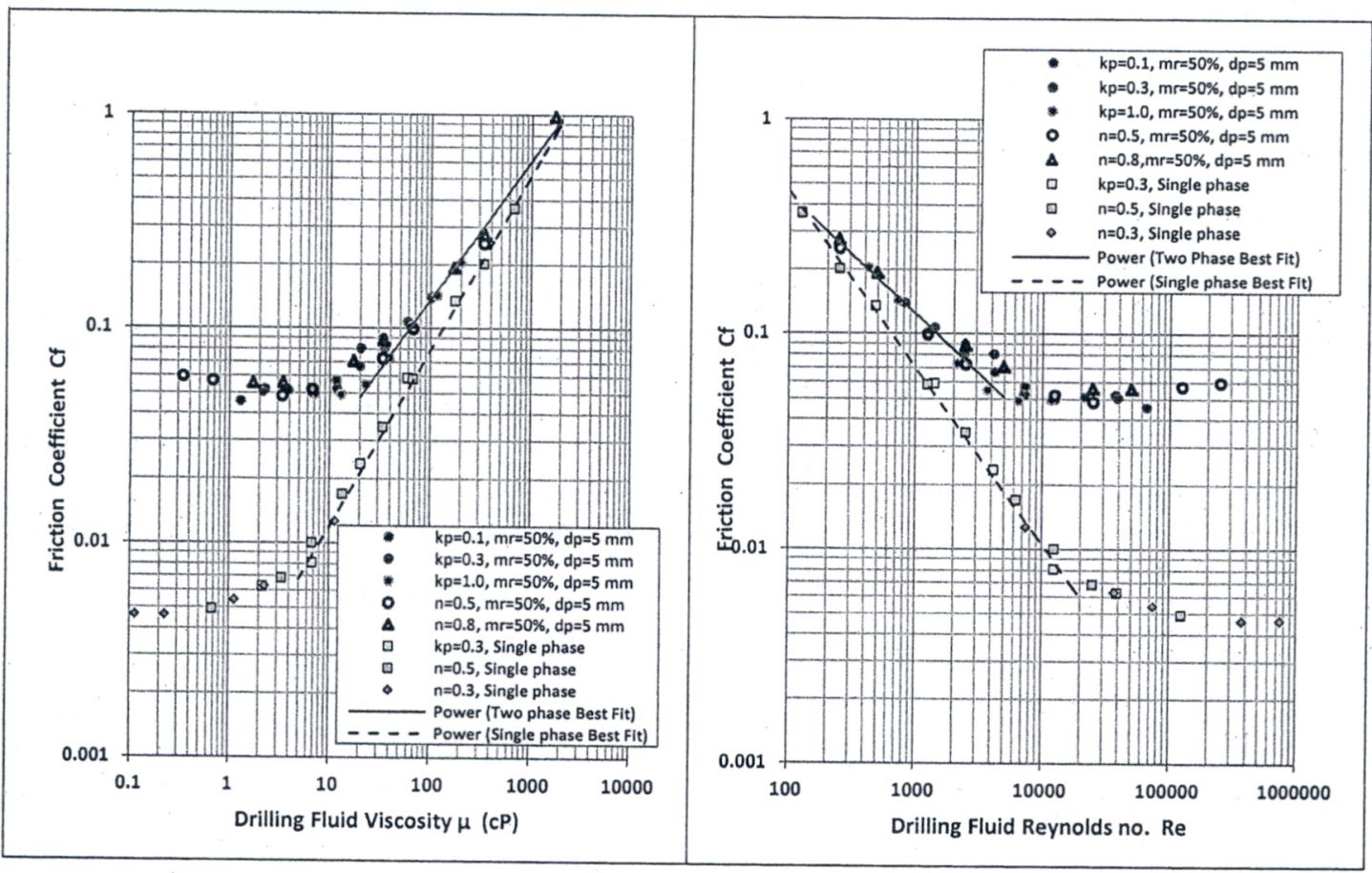

Figure (19): Effect of drilling fluid viscosity $\mu$, and Reynolds number $R e$ on Friction Coefficient $C_{f}$ of the single phase and two phase flows, $L=5 \mathrm{~m}, U_{a v}=1.6 \mathrm{~m} / \mathrm{s}, m r=50 \%, d p=5 \mathrm{~mm}$. 